\title{
INTCAL04 TERRESTRIAL RADIOCARBON AGE CALIBRATION, 0-26 CAL KYR BP
}

\author{
Paula J Reimer ${ }^{1,2} \bullet$ Mike G L Baillie ${ }^{2}$ Edouard Bard $^{3}$ - Alex Bayliss ${ }^{4}$ J Warren Beck ${ }^{5}$. \\ Chanda J H Bertrand ${ }^{6} \cdot$ Paul G Blackwell $^{7}$ Caitlin E Buck $^{7} \cdot$ George S Burr $^{5} \bullet$ Kirsten B Cutler $^{8} \bullet$ \\ Paul E Damon ${ }^{5}$ R Lawrence Edwards ${ }^{8} \bullet$ Richard G Fairbanks $^{9} \cdot$ Michael Friedrich $^{10} \bullet$ \\ Thomas P Guilderson ${ }^{1,17}$ • Alan G Hogg ${ }^{11} \bullet \operatorname{Konrad}$ A Hughen ${ }^{6}$ Bernd Kromer ${ }^{12}$ • \\ Gerry McCormac $^{2} \cdot$ Sturt Manning $^{13,14} \cdot$ Christopher Bronk Ramsey ${ }^{15}$ Ron W Reimer ${ }^{2,16} \bullet$ \\ Sabine Remmele ${ }^{11} \bullet$ John R Southon ${ }^{17} \cdot$ Minze Stuiver $^{18} \bullet$ Sahra Talamo $^{12} \bullet$ F W Taylor ${ }^{19} \bullet$ \\ Johannes van der Plicht ${ }^{20} \bullet$ Constanze E Weyhenmeyer ${ }^{1}$
}

\begin{abstract}
A new calibration curve for the conversion of radiocarbon ages to calibrated (cal) ages has been constructed and internationally ratified to replace IntCa198, which extended from 0-24 cal kyr BP (Before Present, 0 cal BP = AD 1950). The new calibration data set for terrestrial samples extends from 0-26 cal kyr BP, but with much higher resolution beyond $11.4 \mathrm{cal} \mathrm{kyr}$ BP than IntCa198. Dendrochronologically-dated tree-ring samples cover the period from 0-12.4 cal kyr BP. Beyond the end of the tree rings, data from marine records (corals and foraminifera) are converted to the atmospheric equivalent with a site-specific marine reservoir correction to provide terrestrial calibration from 12.4-26.0 cal kyr BP. A substantial enhancement relative to IntCal98 is the introduction of a coherent statistical approach based on a random walk model, which takes into account the uncertainty in both the calendar age and the ${ }^{14} \mathrm{C}$ age to calculate the underlying calibration curve (Buck and Blackwell, this issue). The tree-ring data sets, sources of uncertainty, and regional offsets are discussed here. The marine data sets and calibration curve for marine samples from the surface mixed layer (Marine04) are discussed in brief, but details are presented in Hughen et al. (this issue a). We do not make a recommendation for calibration beyond $26 \mathrm{cal}$ kyr $\mathrm{BP}$ at this time; however, potential calibration data sets are compared in another paper (van der Plicht et al., this issue).
\end{abstract}

\section{INTRODUCTION}

As archaeologists and geoscientists strive for higher resolution and greater chronological controls in their studies, there is a need for continued refinement of the radiocarbon calibration data set to convert ${ }^{14} \mathrm{C}$ ages into calibrated ages. This latest effort to provide a consensus calibration data set for terrestrial and marine samples is the product of the IntCal working group, which met at Queen's University Belfast in April 2002 and at Woods Hole Oceanographic Institute in May 2003. The

${ }^{1}$ Center for Accelerator Mass Spectrometry L-397, Lawrence Livermore National Laboratory, Livermore, California 94550, USA.

${ }^{2}$ School of Archaeology and Palaeoecology, Queen's University Belfast, Belfast BT7 1NN, United Kingdom.

${ }^{3}$ CEREGE, UMR-6635, Europole de l'Arbois BP80, 13545 Aix-en-Provence cdx 4, France.

${ }^{4}$ English Heritage, 23 Savile Row, London, W1S 2ET, United Kingdom.

${ }^{5}$ Department of Physics, University of Arizona, Tucson, Arizona 85721, USA.

${ }^{6}$ Woods Hole Oceanographic Institution, Department of Marine Chemistry \& Geochemistry, Woods Hole, Massachusetts 02543, USA.

${ }^{7}$ Department of Probability and Statistics, University of Sheffield, Sheffield S3 7RH, United Kingdom.

${ }^{8}$ Department of Geology and Geophysics, University of Minnesota, Minneapolis, Minnesota, USA.

${ }^{9}$ Lamont-Doherty Earth Observatory of Columbia University, Palisades, New York 10964, USA.

${ }^{10}$ Institut für Botanik-210, D-70593 Stuttgart, Germany.

${ }^{11}$ Radiocarbon Dating Laboratory, University of Waikato, Private Bag 3105, Hamilton, New Zealand.

${ }^{12}$ Heidelberger Akademie der Wissenschaften, Im Neuenheimer Feld 229, D-69120 Heidelberg, Germany.

${ }^{13}$ The Department of Fine Art, Sidney Smith Hall, 100 St. George Street, University of Toronto, Ontario M5S 3G3, Canada. ${ }^{14}$ Department of Archaeology, University of Reading, P.O. Box 217 Whiteknights, Reading RG6 6AB, United Kingdom.

${ }^{15}$ Oxford Radiocarbon Accelerator Unit, University of Oxford, 6 Keble Rd, Oxford OX2 6JB, England.

${ }^{16}$ Ocean Sciences Department, University of California-Santa Cruz, Santa Cruz, California 92697, USA.

${ }^{17}$ Department of Earth System Science, University of California-Irvine, Irvine, California 92697, USA.

${ }^{18}$ Quaternary Isotope Lab, University of Washington, Seattle, Washington 98195, USA.

${ }^{19}$ Institute for Geophysics, University of Texas, Austin, Texas, USA.

${ }^{20}$ Center for Isotope Research, Groningen University, 9747 AG Groningen, the Netherlands. Also: Faculty of Archaeology, Leiden University, P.O. Box 9515, 2300 RA Leiden, the Netherlands. 
IntCal working group established criteria for acceptance of data into the IntCal calibration data set including general limitations on analytical errors and acceptable scatter and specific record-dependent criteria (Reimer et al. 2002). Specific criteria for tree-ring data sets are reviewed in brief in the following section, while those for marine data sets are discussed in Hughen et al. (this issue a). The data sets were presented and discussed at the 18th International Radiocarbon Conference in Wellington, New Zealand and ratified at the Business Meeting. Suggestions from conference participants have been incorporated into the final product.

This paper focuses on the IntCal04 calibration data set for ${ }^{14} \mathrm{C}$ ages of Northern Hemisphere terrestrial samples. However, because ${ }^{14} \mathrm{C}$ measurements of foraminifera from the Cariaco Basin varved sediments and U-series-dated coral are the basis for the terrestrial calibration data set beyond the beginning of the tree rings at $12.4 \mathrm{kyr}$, we will discuss marine data in brief. The terrestrial calibration for the Southern Hemisphere is discussed in McCormac et al. (this issue). For IntCal04, tree-ring measurements are utilized from 0-12.4 cal kyr BP and marine data, with site-specific, regional reservoir corrections, from 12.4-26 cal kyr BP as illustrated in Figure 1. These data are combined statistically using a random walk model (RWM) described in detail in Buck and Blackwell (this issue). The calibration curve for surface mixed-layer marine samples, Marine04, is constructed from coral and foraminifera ${ }^{14} \mathrm{C}$ measurements from $10.5-26 \mathrm{cal} \mathrm{kyr} \mathrm{BP}$. These data are normalized to the "global" ocean mixed layer by subtracting the difference between the regional reservoir age and the marine model $(\Delta \mathrm{R})$ as defined by Stuiver et al. (1986) and combined via the RWM. Because marine data are sparse from 0 to $10.5 \mathrm{cal}$ kyr BP, a global ocean-atmosphere box diffusion model (Stuiver and Braziunas 1993) is used to deconvolve the ${ }^{14} \mathrm{C}$ production rate from the tree-ring data and calculate the "global" ocean mixed-layer ${ }^{14} \mathrm{C}$ ages for this period. The construction of the calibration data set for marine samples (Marine04) is presented in full in a companion article (Hughen et al., this issue a).

\section{Data Calibration Curve}

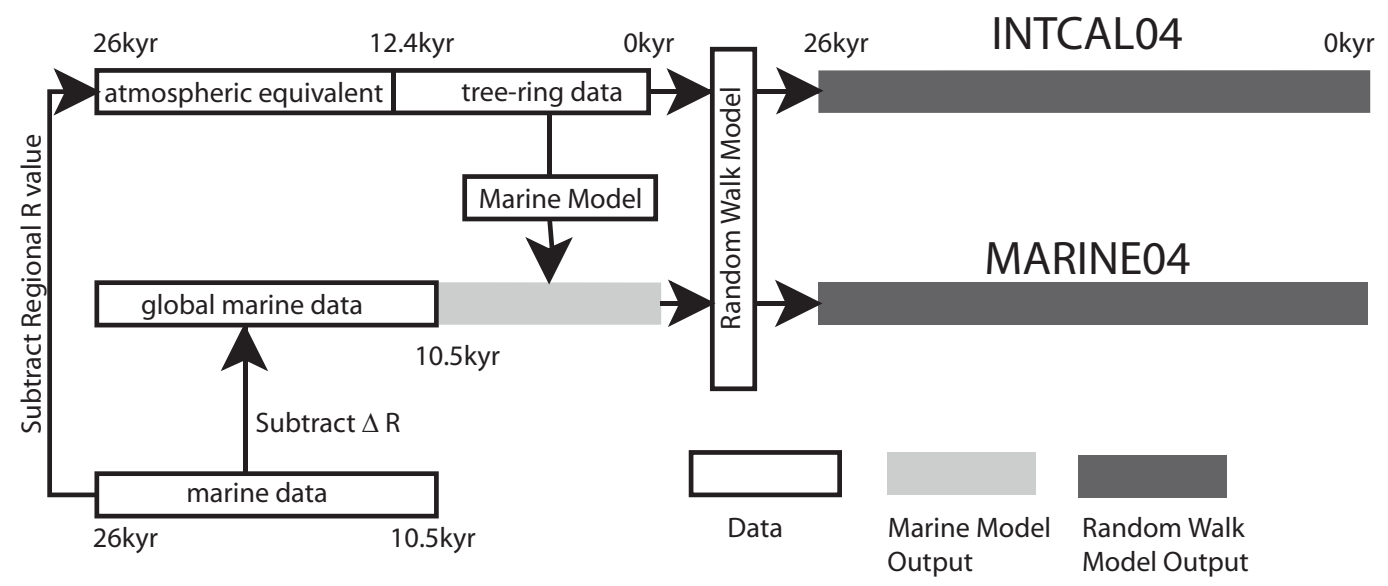

Figure 1 Schematic diagram of IntCa104 and Marine04 calibration data set construction. Tree-ring data extend from 0 to $12.4 \mathrm{cal}$ kyr BP. Beyond the end of the tree rings, coral and foraminifera data are converted to the atmospheric equivalent by subtracting a site-specific reservoir correction $R$. These data are input into the random walk model (RWM) to produce IntCa104. Marine data from 10.5-26.0 cal kyr BP are normalized to the "global" ocean by subtracting $\Delta \mathrm{R}$, the regional difference from the model ocean reservoir age of $405 \mathrm{yr}$. The "global" marine data and the output from the box diffusion model (see main text) are used with the RWM to provide our estimate of the global marine calibration curve Marine 04 . 
We do not make a recommendation for calibration beyond 26 cal kyr BP because disparities between ${ }^{14} \mathrm{C}$ data sets are large and have not been resolved. The strengths and weaknesses of various ${ }^{14} \mathrm{C}$ data sets beyond $26 \mathrm{cal} \mathrm{kyr} \mathrm{BP}$ are discussed by van der Plicht et al. (this issue). These include U/Th-dated speleothems (Beck et al. 2000; Weyhenmeyer et al. 2003), macrofossils from varved lake sequences (Kitagawa et al. 2000), U/Th-dated aragonite from Lake Lisan (Schramm et al. 2000; van der Borg et al. 2004), foraminifera from marine sediments with proxies matched to the ice-core time scales (Bard et al., this issue; Hughen et al. 2004; Voelker et al. 2000; van Kreveld et al. 2000), and U/Th-dated corals (Bard et al. 1998; Cutler et al., this issue). We actively discourage the use of subjectively assembled "calibration" curves from disparate data sets; these are not recognized as "calibration" by the international community and should not be published as such.

\section{THE INTCAL04 DATA SETS}

The data sets used in the IntCal04 calibration are given in full as supplemental material on the Radiocarbon Web site (www.radiocarbon.org) and are also available at www.calib.org. Uncertainties are given for the data set ages and the calibrated or cal time scales in order that they may be combined properly, since in some cases the cal time scale errors are not independent. Replicate ${ }^{14} \mathrm{C}$ measurements within a laboratory or made by two or more laboratories are given separately, when available. These data are not necessarily completely independent estimates of the underlying calibration curve, since they are derived from the same samples, but have been included for completeness.

\section{Tree-Ring Data Sets (0-12.4 cal kyr BP)}

For inclusion in the calibration data set, dendrochronological dating and cross-checking of tree rings is required. A few exceptions were made for post-AD 1320 Douglas firs (Pseudotsuga menziesii), which have robust ring production in the Pacific Northwest environment. Calendar ages for these trees, which had well-known felling dates, were determined by ring counting after inspection of the well-developed rings by H C Fritts (Stuiver 1982). X-ray densitometry was later used to confirm the ring counts.

The Holocene part of the ${ }^{14} \mathrm{C}$ calibration is based on several millennia-long tree-ring chronologies, providing an annual, absolute time frame within the possible error of the dendrochronology, which was rigorously tested by internal replication of many overlapping sections. Whenever possible, they were cross-checked with independently established chronologies of adjacent regions. The German and Irish oak chronologies were cross-dated until back into the 3rd millennium BC (Pilcher et al. 1984), and the German oak chronologies from the Main River, built independently in the Göttingen and Hohenheim tree-ring laboratories, cross-date back to 9147 cal BP (Spurk et al. 1998). The North American trees that form part of the ${ }^{14} \mathrm{C}$ calibration curve prior to AD 1320 were cross-dated with either the Sequoiadendron master chronology or with a Pacific Northwest Douglas fir chronology (Stuiver 1982).

Due to periodic narrow rings caused by cockchafer beetles, some German oak samples were excluded from IntCa198. Analysis of these tree rings, with an understanding of the response of trees to the cockchafer damage, allowed some of these measurements to be re-instated in the chronology (Friedrich et al., this issue).

The 2 parts of the German Preboreal pine chronology (PPC), which were formerly floating, have been linked and cross-matched dendrochronologically to the absolutely-dated Holocene oak chronology. Including additional new finds, the south German part of the PPC is prolonged into the 
Younger Dryas and now starts at $11,993 \mathrm{cal}$ BP. New pine chronologies from Switzerland and eastern Germany extend the PPC to 12,410 cal BP (Friedrich et al., this issue).

\section{The Heidelberg Data Set}

${ }^{14} \mathrm{C}$ measurements of the wood from the German pine chronology, the Lake Neufchatel chronology, and a new larch series provide terrestrial calibration extending back to $12,410 \mathrm{cal} \mathrm{BP}$. In addition, intervals were measured to fill gaps in the tree-ring ${ }^{14} \mathrm{C}$ record resulting from previous shifts or cockchafer-damaged sections that could not be re-instated (Friedrich et al., this issue). Additional decadal measurements of German oak have been made for the periods 2570-2800 cal BP and 3440-3640 cal BP. The oak samples were pretreated with acid-alkali-acid (de Vries method), whereas the pines underwent an additional soxhlet extraction to remove resins (Becker and Kromer 1986; Kromer et al. 1986).

\section{The Belfast Data Set}

Recent ${ }^{14} \mathrm{C}$ measurements of $\alpha$-cellulose extracted from decadal sections of Belfast Irish oak over the past $1000 \mathrm{yr}$ (Hogg et al. 2002) and for the period 1220-1460 BP (McCormac et al., this issue) have been included. Comparisons of these measurements with the 1986 and 1993 Irish oak data sets (Pearson et al. 1993; Pearson et al. 1986), as well as with Irish oak measurements made in Seattle, resulted in the acceptance of the original 1986 Irish oak data sets over the corrected 1993 data sets (Hogg et al. 2002). Decadal measurements from the 1986 data set have been included separately rather than averaged to bidecadal intervals, where possible. In cases where decadal measurements had been averaged with bidecadal measurements, the original bidecadal data could not be retrieved, so are included as published. In those cases, the decadal data are redundant and are not included. The pre-1993 oak measurements were made on samples processed to holocellulose (Pearson et al. 1986). German oak measurements are used as originally published (Pearson et al. 1993). A further 3 decadal samples of Irish oak from 3450-3470 cal BP were measured to check the earlier Irish oak bidecadal data where they differed considerably from the German oak. These samples were pretreated to $\alpha$-cellulose at Queen's University Belfast and measured at both Queen's University Belfast and the Center for Accelerator Mass Spectrometry, Lawrence Livermore National Laboratory.

\section{The Waikato Data Set}

Decadal sections of Belfast Irish oak wood from 0-1000 cal BP were pretreated to $\alpha$-cellulose and measured at the Waikato Radiocarbon Laboratory (Hogg et al. 2002).

\section{The Seattle Data Set}

With the exception of some changes in tree-ring calendar ages in the German pine and oak series (Friedrich et al., this issue) and re-instatement of some cockchafer-damaged sections as described above, the University of Washington Quaternary Isotope Lab data set is the same as detailed in 1998 (Stuiver et al. 1998a). This data set includes wood from Washington, Oregon, California, and Alaska for the period of 0 to $2099 \mathrm{cal} \mathrm{BP}$ and from Germany for 1900 to 11,673 cal BP. With the exception of a portion of the Pacific Northwest samples from 35-2095 cal BP which were processed with the de Vries method, all samples were processed to $\alpha$-cellulose.

\section{The Pretoria and Groningen Data Sets}

${ }^{14} \mathrm{C}$ measurements of German oak made at Pretoria and Groningen were published together in 1993 to provide a calibration for short-lived samples (Vogel and van der Plicht 1993). Both laboratories 
used a similar acid-base-acid (de Vries method) pretreatment (de Jong et al. 1986; Vogel et al. 1986). The Groningen data set has been revised slightly in the past after discovery of an error in tree-ring counts (de Jong et al. 1989). No changes have been made to these data sets since published in 1993.

\section{The Arizona Data Set}

The relation between North American and European wood has been studied using bristlecone pine (BCP) and European oak (German oak and Irish oak), respectively. Discrepancies have become evident over the years, in particular when the German oak was corrected by a dendro-shift of $41 \mathrm{yr}$ towards older ages (Kromer et al. 1996). Attempts were made to resolve the discrepancies by remeasuring BCP samples, measured earlier in Tucson (Linick et al. 1986). The University of Arizona Laboratory of Tree-Ring Research provided dendrochronologically-dated bristlecone pine samples to Heidelberg (wood from around 4700 and $7600 \mathrm{cal} \mathrm{BP}$ ), Groningen (around $7500 \mathrm{cal} \mathrm{BP}$ ), Pretoria (around $4900 \mathrm{cal} \mathrm{BP}$ ), and Seattle (around $7600 \mathrm{cal} \mathrm{BP}$ ). The replicate measurements have a mean offset of $37 \pm 6{ }^{14} \mathrm{C}$ yr $(n=21)$ from the Tucson measurements. Applying this shift to the Tucson data results in a close fit to the wiggles of the German oak, which would not occur if there were an error in the dendrochronology of either series. Because of this offset, the IntCal working group has decided not to include the BCP record in IntCal04.

\section{Sample Pretreatment Differences}

Tree-ring samples included in IntCal04 have been pretreated either with variations on the de Vries method, which removes sugars, resins, tannins, and part of the lignin, or extracted to holocellulose or $\alpha$-cellulose as noted above. Because compounds from subsequent years may be deposited in sapwood, some differences may result in the ${ }^{14} \mathrm{C}$ content of wood pretreated by different methods. Stuiver and Quay (1981) showed that the de Vries method removed about $90 \%$ of the later additions in Douglas fir. Since most pre-bomb variations in atmospheric ${ }^{14} \mathrm{C}$ are in the range of $10 \%$ per year or less, the de Vries method would result in a difference of only a tenth of a mill or $<1{ }^{14} \mathrm{C}$ yr. Oak showed differences in $\delta^{13} \mathrm{C}$ between samples processed by the de Vries method and that extracted to either holocellulose or $\alpha$-cellulose, also indicating that not all lignin was removed in the de Vries method (Hoper et al. 1998). The difference in ${ }^{14} \mathrm{C}$ ages resulting from different pretreatment methods is therefore likely to be small, but the difference may contribute to the excess variance observed in interlaboratory comparisons, which are discussed in a subsequent section.

\section{Marine Data Sets, 12.4-26 kyr BP}

From 12.4-26 kyr BP, IntCal04 is based on marine data sets with site-specific reservoir corrections. Coral records provide calibration data for the period from 12.4 to 26 cal kyr BP (Bard et al. 1998; Fairbanks et al., forthcoming; Cutler et al., this issue; Burr et al., this issue) with foraminifera records included for the period from 12.4 to $14.7 \mathrm{cal} \mathrm{kyr} \mathrm{BP} \mathrm{(Hughen} \mathrm{et} \mathrm{al.,} \mathrm{this} \mathrm{issue} \mathrm{b).} \mathrm{The} \mathrm{reser-}$ voir corrections for all sites are assumed to have been constant with time with an uncertainty calculated from the overlap with the tree-ring measurements. The reservoir uncertainty is added in quadrature to the measurement uncertainty. The marine data sets and reservoir corrections are discussed in detail in Hughen et al. (this issue b) and Cutler et al. (this issue).

\section{REGIONAL OFFSETS}

For the purposes of constructing a Northern Hemisphere calibration data set, the trees used for IntCal04 are assumed to have sampled a well-mixed atmosphere. Latitude-dependent differences in ocean area, surface water ages, and wind speeds are expected to cause ${ }^{14} \mathrm{C}$ offsets of $\sim 1 \%$ ( $\left({ }^{14} \mathrm{C} \mathrm{yr}\right)$ for most of the Northern Hemisphere with the exception of the high Arctic (Braziunas et al. 1995). 
Measurement of regional offsets in the Northern Hemisphere is difficult because they are near the precision limit for ${ }^{14} \mathrm{C}$. This difficulty is compounded by laboratory offsets (unless samples from each region are measured in the same laboratory and ideally at the same time) and by potential dendrochronological errors. Regional offsets between the primarily mid-latitude sites of the IntCal04 trees have been noted for various time periods, but may not be constant (Stuiver et al. 1998a). These regional offsets were neglected, with the exception of ${ }^{14} \mathrm{C}$ measurements of an Alaskan tree which were normalized to the Pacific Northwest trees by adding the average offset of $14 \pm 3 \mathrm{yr}$ as reported in Stuiver et al. (1998a). Regional offsets may also result from growing season differences, altitudinal effects, or proximity to areas of intense ocean upwelling, melting permafrost, or volcanic emissions, and are potentially significant for certain localities and time periods (Damon et al. 1996; Dellinger et al. 2003; Kromer et al. 2001; Manning et al. 2001; Sakamoto et al. 2003). The time-varying nature of such signals, even if they can be detected, precludes an easy correction in the calibration process (Manning et al. 2002). Insufficient data exists at present to construct regional calibration data sets for any extended length of time, with the exception of the Southern Hemisphere. The Southern Hemisphere calibration data set (SHCal04) and the distinction between Southern and Northern Hemisphere atmospheric boundaries are discussed in more detail in McCormac et al. (this issue).

\section{SOURCES OF UNCERTAINTY}

Counting statistics do not represent all the uncertainty in ${ }^{14} \mathrm{C}$ ages. Additional sources of uncertainty may be the result of differences in sampling, sample pretreatment, or laboratory operation, which are difficult to quantify for individual samples. The excess variance can be described by comparing the standard deviation in the ${ }^{14} \mathrm{C}$ age difference of replicate samples $\left(\sigma_{2}\right)$ with the expected standard deviation based on the counting statistics $\left(\sigma_{1}\right)$. One approach to estimating $\sigma_{2}$ is to assume that it is proportional to $\sigma_{1}$; it is then convenient to express this relationship through a laboratory error multiplier, $k$, where $k=\sigma_{2} / \sigma_{1}$ (Stuiver 1982). These $k$-value estimates should not be used implicitly as a mechanism to determine the added variance in sample handling and analysis relative to pure counting statistics, because not all laboratories base their results only on counting statistics. For instance, the Belfast and Waikato 2002 data sets include laboratory error multipliers of 1.125 and 1.125-1.176, respectively, in the reported errors, and the Arizona NSF accelerator facility and the Center for Accelerator Mass Spectrometry use the larger of the counting statistics uncertainty and the standard deviation in multiple acquisition cycles on the same AMS target to calculate errors on individual samples (Donahue et al. 1997; Guilderson et al. 2003). Regional differences and laboratory practices may also contribute to the variability between laboratories that are not accounted for by laboratory estimates of total error. Nevertheless, for the purpose of constructing a Northern Hemisphere calibration data set, an interlaboratory/inter-regional error multiplier was determined for each of the data sets relative to the Seattle measurements for the same period. The Seattle data set was chosen for this purpose because it includes a large number of replicates and the measurements span most of the period of the tree-ring calibration. An error multiplier of 1.3 was first determined for the Seattle single-year tree-ring data by evaluation of the number of points outside of 2 standard deviations from the mean. Because most of the replicates were re-measured due to some inconsistency with the other data, this error multiplier can be considered an upper limit. This agrees with an upper limit for $k$ for the Seattle data from an earlier comparison between the laboratories that included trees from different regions (Stuiver et al. 1998a). With $k=1.3$ assigned to the Seattle data, we could then assign the remaining variability to the other data sets. Data for each lab was binned into 10-yr intervals and averaged. Because changes in laboratory procedures and the inclusion of a laboratory error multiplier in recent Belfast results may have affected the interlaboratory error multipliers, we divided the Belfast and Heidelberg data sets, which were measured over the span of several decades, into 2 time 
periods for this analysis (Table 1), and also separated the earlier Belfast data set into Irish oak and German oak. There was not a large difference in the calculated $k$ values between early and recent measurements in the Belfast lab for the Irish oak samples when the previously applied laboratory error multiplier on the more recent data set is considered; however, the early measurements of German oak were more variable than those of Irish oak. The recent Heidelberg data sets had smaller $k$ values than older measurements. The reason for the early variation is partly due to the fact that these samples were measured to help place a tree in the dendrochronology as it was being built instead of measured consecutively, and also because many of these samples contain only a few tree rings but are being compared to decadal samples. The values of $k$ in Table 1 were applied to the errors for the tree-ring data sets prior to application of the RWM. Laboratory or data set error multipliers for the marine data sets are discussed in Hughen et al. (this issue a). It will be noted that the Seattle data are generally somewhat younger (positive offset) than the results for the other data sets (Table 1). Unlike IntCa198, no interlaboratory offset corrections were made to the ${ }^{14} \mathrm{C}$ ages.

Table 1 Laboratory offsets and error multipliers for the Belfast, Pretoria/Groningen (P/G), Heidelberg, and Waikato laboratories ${ }^{14} \mathrm{C}$ measurements of dendro-dated wood compared to Seattle measurements for the same time periods, assuming $k=1.3$ for Seattle (see text). The offset from the Seattle data set equals the weighted mean ${ }^{14} \mathrm{C}$ age difference of samples for which the mid-point cal ages fall within the same decade. $\sigma_{1}$ is the predicted average standard deviation in single ${ }^{14} \mathrm{C}$ age comparisons (based on quoted laboratory errors); $\sigma_{2}$ is the observed standard deviation in the age and $n$ is the number of comparisons. The $\sigma_{2} / \sigma$ ratio $=k$. Offset, $\sigma_{1}$, and $\sigma_{2}$ are in ${ }^{14} \mathrm{C}$ yr. The $k$ values marked with an asterisk include previously applied laboratory error multipliers.

\begin{tabular}{lrllllr}
\hline Laboratory & Offset & \multicolumn{1}{l}{$\sigma_{1}$} & \multicolumn{1}{l}{$\sigma_{2}$} & $k$ & \multicolumn{1}{l}{$n$} & \multicolumn{1}{c}{$\begin{array}{l}\text { Cal yr interval } \\
\text { (cal BP) }\end{array}$} \\
\hline Belfast Irish oak 1986 & $-6 \pm 1$ & 21.5 & 29.4 & 1.37 & 407 & $110-7160$ \\
Belfast German oak 1993 & $18 \pm 2$ & 27.5 & 48.5 & 1.76 & 148 & $6900-9850$ \\
Belfast Irish oak 2002, 2004 & $4 \pm 2$ & 21.3 & 27.6 & $1.21^{*}$ & 124 & $5-3470$ \\
Pretoria/Groningen 1993 & $18 \pm 2$ & 25.0 & 27.9 & 1.12 & 194 & $3885-5855$ \\
Heidelberg Hd\# $<15000$ & $27 \pm 2$ & 37.1 & 50.2 & 1.35 & 228 & $6045-11,655$ \\
Heidelberg Hd\# $>15000$ & $15 \pm 3$ & 31.5 & 37.0 & 1.19 & 86 & $2575-11,655$ \\
Waikato & $10 \pm 2$ & 22.0 & 22.9 & $1.04^{*}$ & 100 & $5-995$ \\
\hline
\end{tabular}

Uncertainty in single-ring cal ages for dendrochronologically-dated wood is on the order of $1 \mathrm{yr}$ for highly replicated and cross-checked chronologies and is therefore ignored in the analysis. For a ${ }^{14} \mathrm{C}$ date on a multiple-year block of wood, there are potentially 2 further effects to be taken into account. Firstly, the ${ }^{14} \mathrm{C}$ measurement in such a case is an average over a period in which the true curve will have changed by an unknown amount; the uncertainty that this adds is taken into account in the RWM, which explicitly allows for year-on-year changes in the underlying curve (see Buck and Blackwell, this issue), unlike in IntCal98 where it was essentially ignored. Secondly, this average may be based on an unequal amount of carbon from each ring; if the actual proportions are unknown, this introduces an additional small uncertainty. A worst-case offset of $2 \mathrm{yr}$ in calendar age was determined from the annual tree-ring data (Stuiver et al. 1998) in terms of moving decade age compared to IntCal98 (Manning et al. 2001). A comparison of annual to decadal tree-ring ${ }^{14} \mathrm{C}$ measurements of a single Douglas fir tree from 440-250 cal BP (see supplemental data) gives a mean offset of $5.5 \pm 4.4{ }^{14} \mathrm{C}$ yr. The larger uncertainty due to loss of wood from saw cuts in some early 
sample preparations (M Friedrich, personal communication) is more critical and hard to define because wood often does not have exactly vertical ring divisions, so sawing could include or exclude one or even several rings for part of the sample under the initial surface. This is especially likely for narrow rings or for smaller tree sections where curvature comes into play. Dissecting of tree rings can be difficult depending on the species and size of rings, but with care only a small amount of wood from the current ring is lost or additional wood from an adjacent ring included. At present, these effects are ignored for simplicity, although the RWM could readily incorporate such information if it was available.

\section{CALIBRATION CURVE CONSTRUCTION}

IntCal98 was constructed by taking a weighted average of all data within a 10 -yr window and assigning the mid-point of the decade as the cal age. Bidecadal tree-ring ${ }^{14} \mathrm{C}$ measurements were treated as if there had been 2 decadal measurements, and sub-decadal measurements were treated as if they were decadal. The uncertainty in the calendar age of varved sediments and U/Th-dated coral was not considered. For IntCal04, a coherent statistical method was used (Buck and Blackwell, this issue) based on a stochastic model for the underlying ${ }^{14} \mathrm{C}$ calibration curve, taking into account the calendar age span (e.g. number of tree rings or varves) and calendar age uncertainty of the samples as well as ${ }^{14} \mathrm{C}$ age uncertainty. The estimation allows for the covariance between observations due to the structure of the model and to dependence between the calendar age uncertainty of related observations (e.g. those with varve-counting or wiggle-matching errors in common). The model for the curve takes the form of a random walk, with the changes in the curve from one year to the next represented by a Gaussian distribution with a mean of $\beta$ and variance per year of $r^{2}$. Because there are usually many observations relevant to the estimated ${ }^{14} \mathrm{C}$ age for a given calendar year, the calculation is carried out within a window of at least 100 observations. The value for the parameter $r$ was derived from sensitivity tests on single-year tree-ring measurements of the past $500 \mathrm{yr}$ (Stuiver et al. 1998b). The single-year tree-ring measurements were initially selected for the model parameterization in order to retain as much signal as possible, but essentially the same value for $r$ was obtained using decadal measurements in selected portions of the tree-ring data set. The parameter selection details are given in Buck and Blackwell (this issue). The IntCal04 ${ }^{14} \mathrm{C}$ calibration curve is generated by the model at intervals of $5 \mathrm{yr}$ for the range $0-12.4 \mathrm{cal} \mathrm{kyr} \mathrm{BP}, 10 \mathrm{yr}$ for 12.4-15 cal kyr BP, and $20 \mathrm{yr}$ for 15-26 cal kyr BP.

\section{DISCUSSION}

For comparison purposes, we calculated a weighted average of all updated tree-ring ${ }^{14} \mathrm{C}$ measurements within a 10-yr window. This $10-\mathrm{yr}$ binned data set is equivalent to the procedure used to construct IntCa198. The RWM assumes that there is equal probability of a rise or fall in atmospheric ${ }^{14} \mathrm{C}$ levels around the mean value of $\beta$. Because ${ }^{14} \mathrm{C}$ production increases may be more rapid than the subsequent redistribution in the global carbon reservoirs, we tested the validity of this assumption by calculating the distribution of shifts from one decade to the next. These shifts are normally distributed in both the binned tree-ring data set and IntCal04 (Figure 2), indicating that the assumption is valid.

To evaluate the effect of the RWM on the periodic nature of the ${ }^{14} \mathrm{C}$ data, we examined the spectral properties of the $\Delta^{14} \mathrm{C}$ calculated from the IntCal04 calibration curve from 2400-100 BP, so that no detrending was necessary. Both data sets contained significant spectral power at about $90 \mathrm{yr}$ and $200 \mathrm{yr}$ with approximately the same amplitude using a fast fourier transform with confidence limits (Mitchell et al. 1966). The 205 -yr cycle was phase-shifted by -0.3 degrees and the 88 -yr cycle by +10.8 degrees in IntCal04 relative to the binned tree-ring data set, which indicates that geophysical 


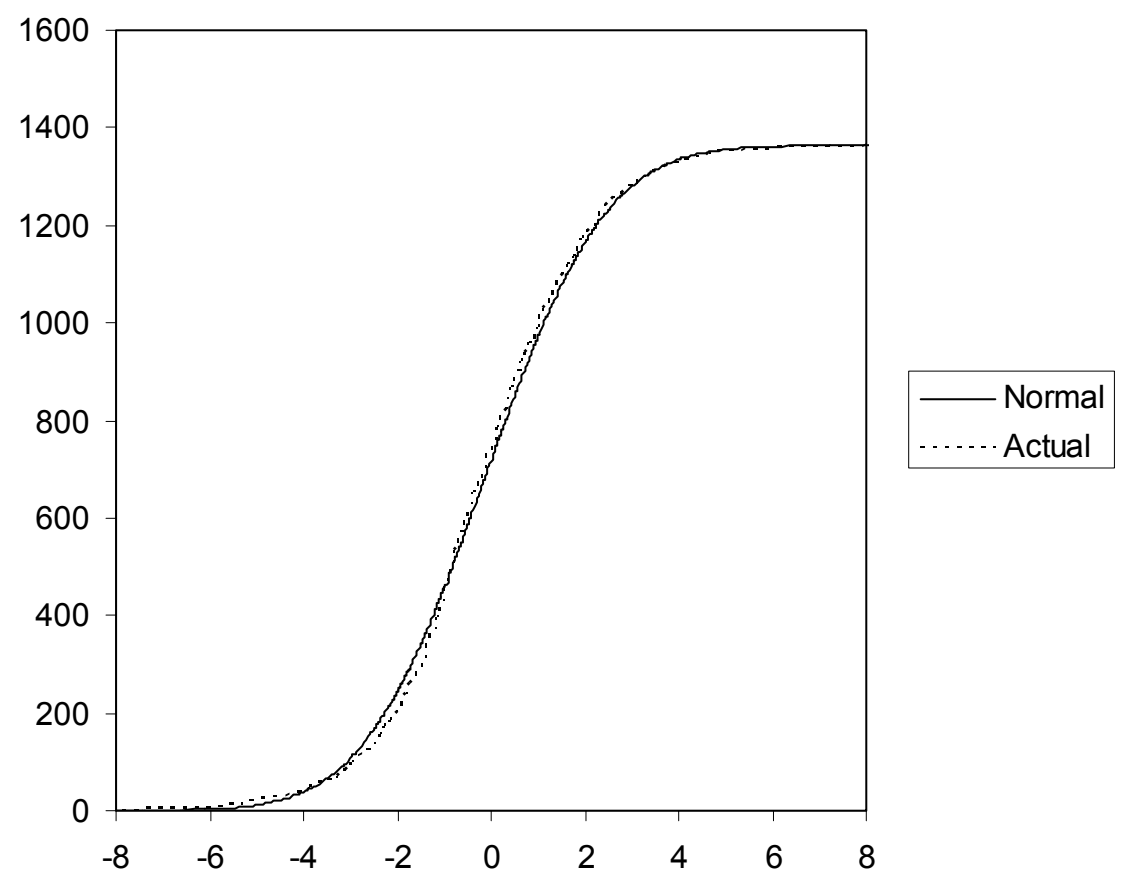

Figure 2 Cumulative distribution of decay-corrected decadal shifts in IntCal04 for the period 13,950 to $10,000 \mathrm{cal} \mathrm{BP}$. The cumulative number of decades is plotted against the shift in ${ }^{14} \mathrm{C}$ yr; this is compared to a Normal distribution with the same mean and standard deviation.

variations on decadal and centennial scales are preserved in IntCal04. Attenuation of the signal and a larger phase shift for higher-frequency components is possible, so caution is in order when comparing cycles with other records.

Wiggle-matching to the IntCal04 calibration data set may require some adjustment in the methods in use, particularly with shorter series. The fit for shorter series may also be significantly affected by the smoother curve of IntCal04 relative to IntCa198. The more general issue here is in the methodology used for fitting. The usual underlying assumption is that the points on the calibration curve can be treated as independent observations, whereas, in fact, they are syntheses of possibly overlapping data sets. In principle, this will be a problem for any analysis where the terms in the likelihood function are combined as if this assumption of independence were true. In practice, the uncertainties in the measurements are usually much higher than those in the curve, so this is not of any practical significance. In the case of wiggle-matching of tree-ring sequences, the method is sometimes being pushed to the limits in all respects. In these cases, it may be necessary to incorporate the fitted data and the original calibration data in a full Bayesian analysis (see Buck and Blackwell, this volume); such an approach could of course be used in all cases.

\section{CONCLUSIONS}

Because the RWM accounts for scatter around the "true calibration curve," the IntCal04 curve is somewhat smoother than the tree-ring-derived portion of IntCal98 (0-11,440 cal BP), except where there are measurements on 1-3-yr pieces of wood (Figure 3a). The addition of new data in certain time periods also results in tighter constraints on the curve in places (Figure 3b). The most significant changes (Figure 3c-e) are of course due to the extension of the German dendrochronology from 11.4 to 12.4 cal kyr BP (Friedrich et al., this issue), the new high-resolution Cariaco Basin data set from 
10.5 to 14.7 cal kyr BP (Hughen et al., this issue b; Hughen et al. 2000), and extensive new coral data sets from 12.4 to $26 \mathrm{cal}$ kyr BP (Fairbanks et al., forthcoming; Cutler et al., this issue; Burr et al., this issue). The resulting difference in calibrated age ranges may be substantial in these cases-e.g., a hypothetical ${ }^{14} \mathrm{C}$ age of $11,000 \pm 100{ }^{14} \mathrm{C}$ BP yields $95 \%$ cal age ranges of cal BP $12,650-12,730$ and 12,810-13,190 with IntCal98, and cal BP 12,820-13,100 with IntCal04 (Figure 4).

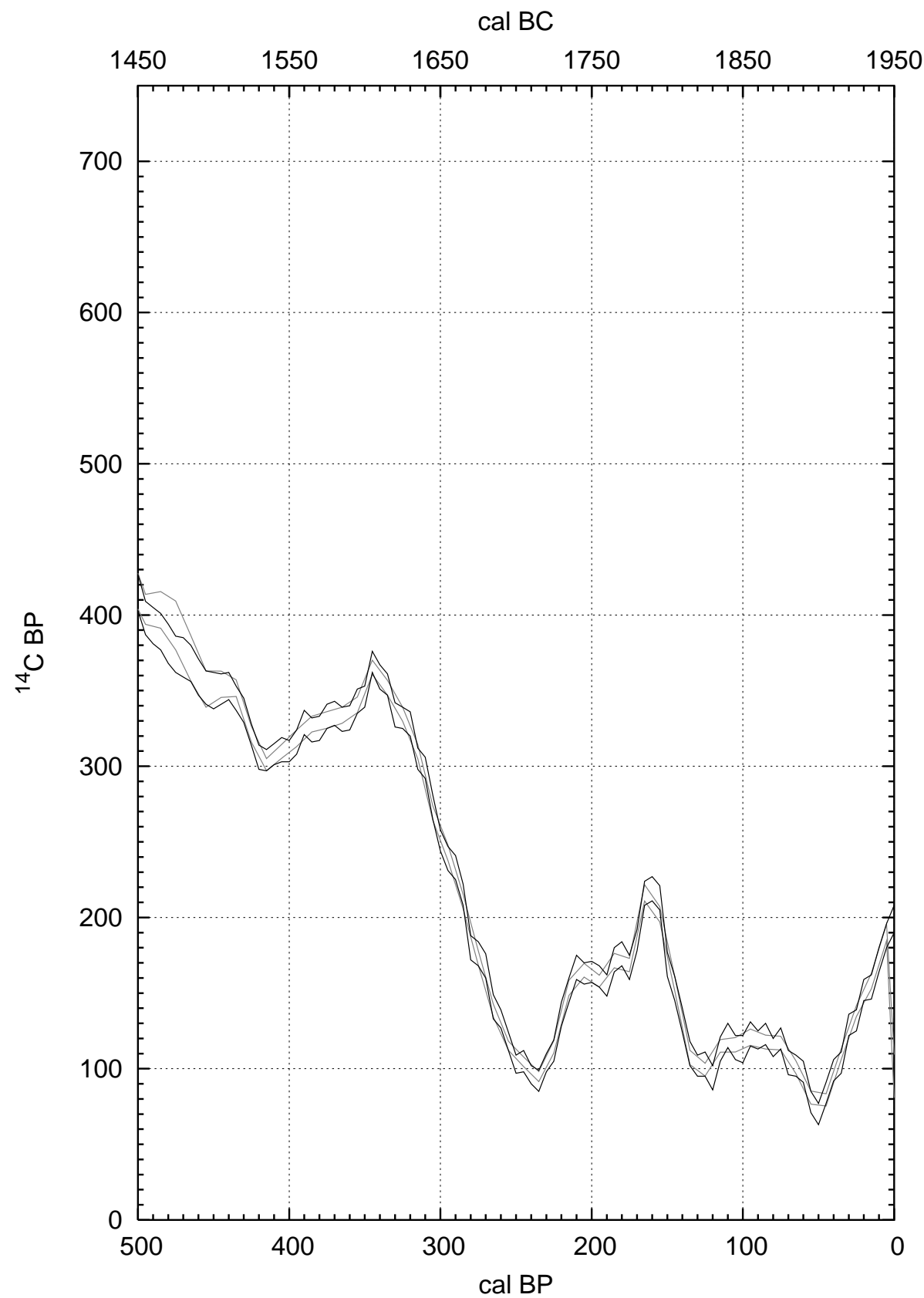

Figure 3a IntCa198 (gray lines) and IntCal04 (black lines) 1-standard deviation error envelopes for $0-500 \mathrm{cal}$ BP. 


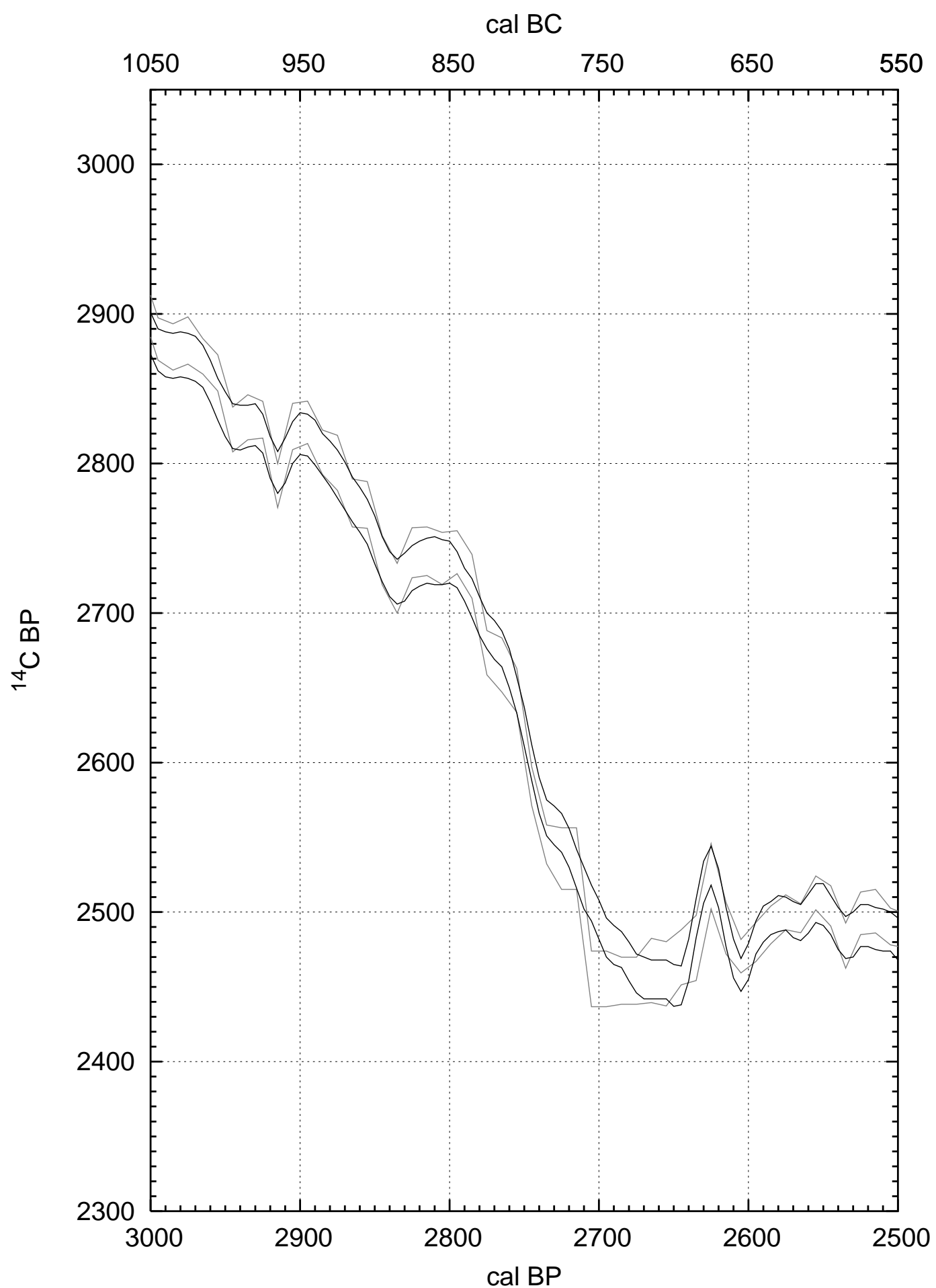

Figure 3b IntCa198 (gray lines) and IntCal04 (black lines) 1-standard deviation error envelopes for 2500-3000 cal BP. 


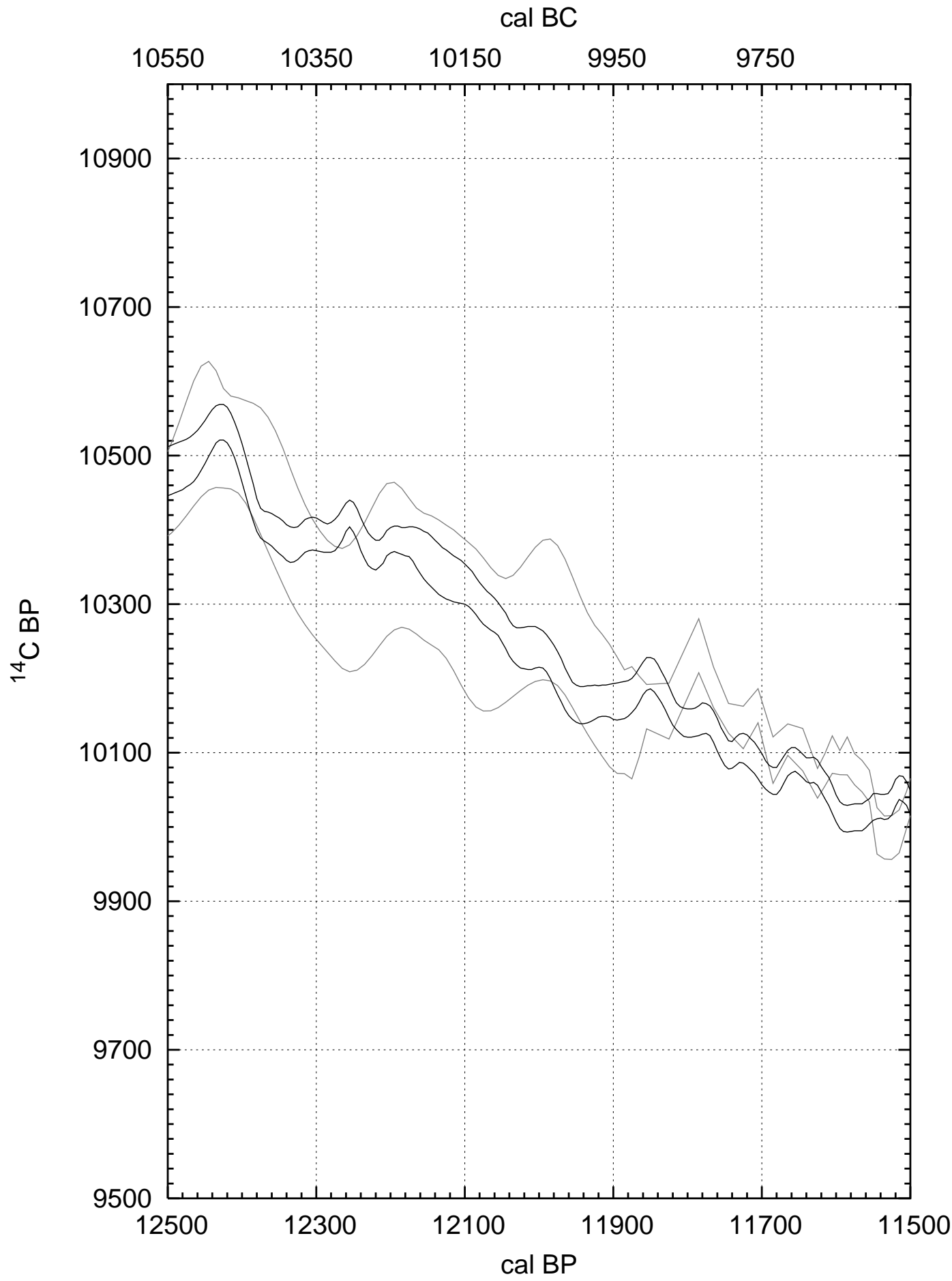

Figure 3c IntCa198 (gray lines) and IntCa104 (black lines) 1-standard deviation error envelopes for 11,500-12,500 cal BP. 


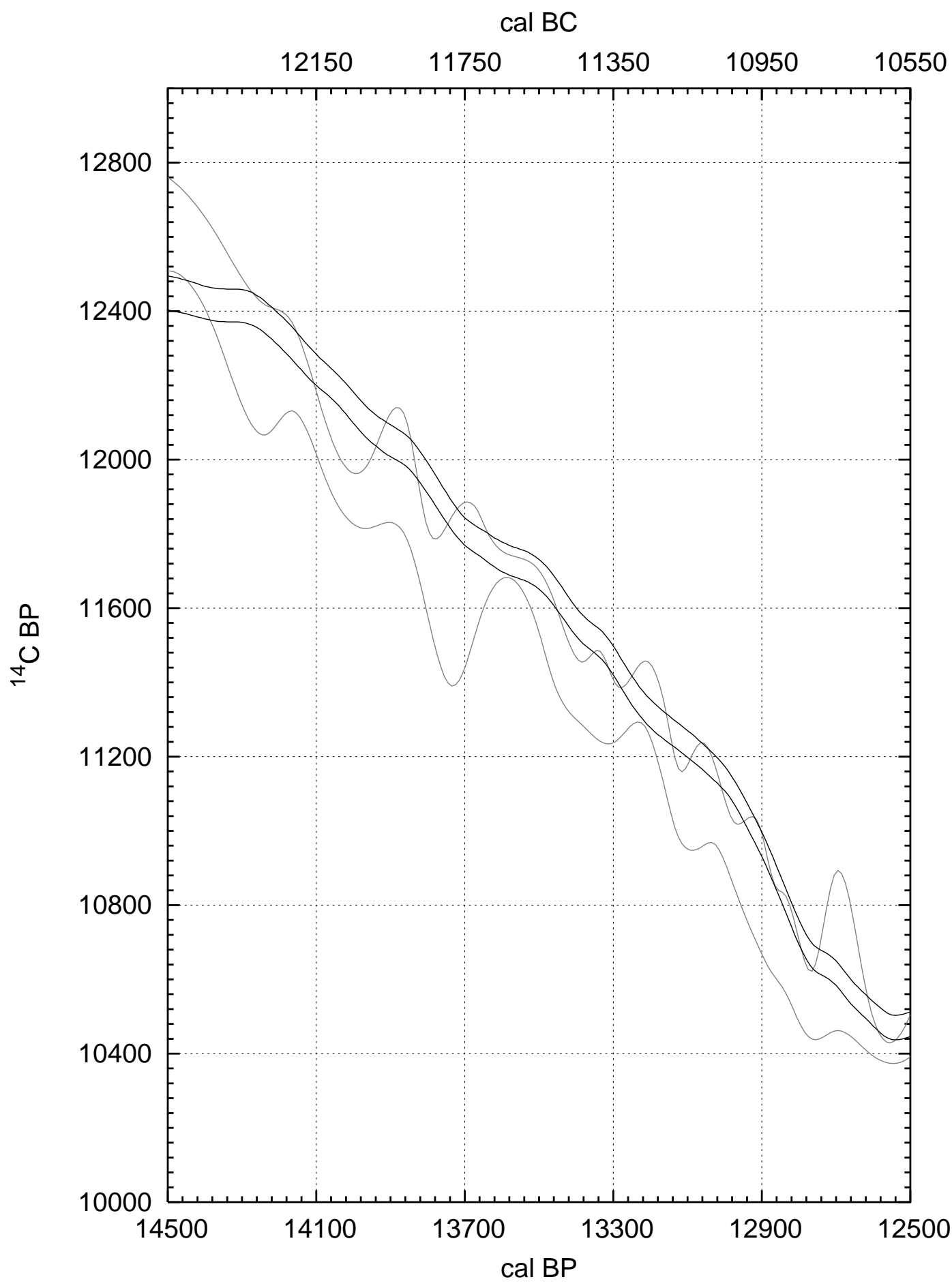

Figure 3d IntCa198 (gray lines) and IntCa104 (black lines) 1-standard deviation error envelopes for 12,500-14,500 cal BP. 


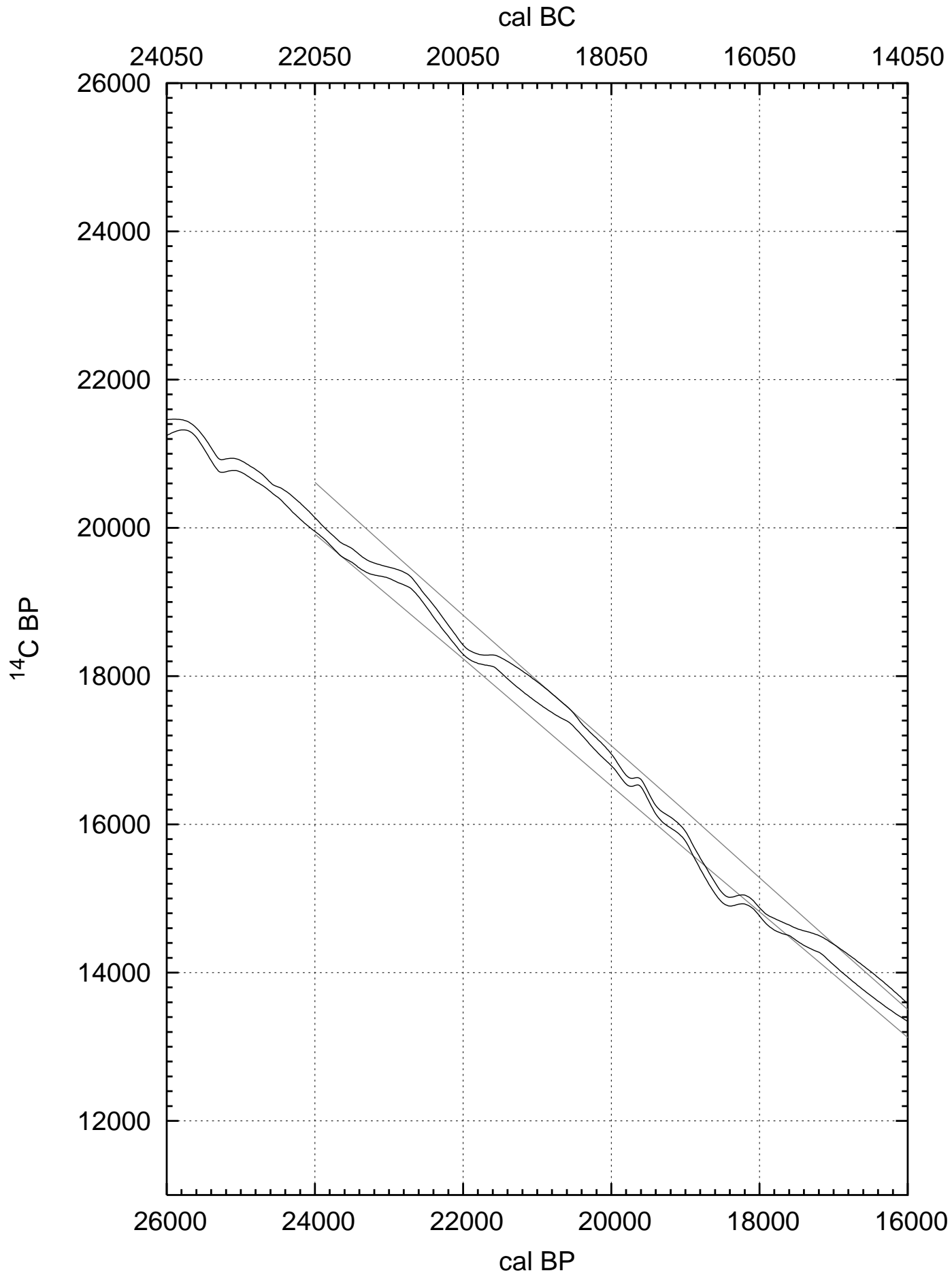

Figure 3e IntCa198 (gray lines) and IntCal04 (black lines) 1-standard deviation error envelopes for 16,000-26,000 cal BP. 


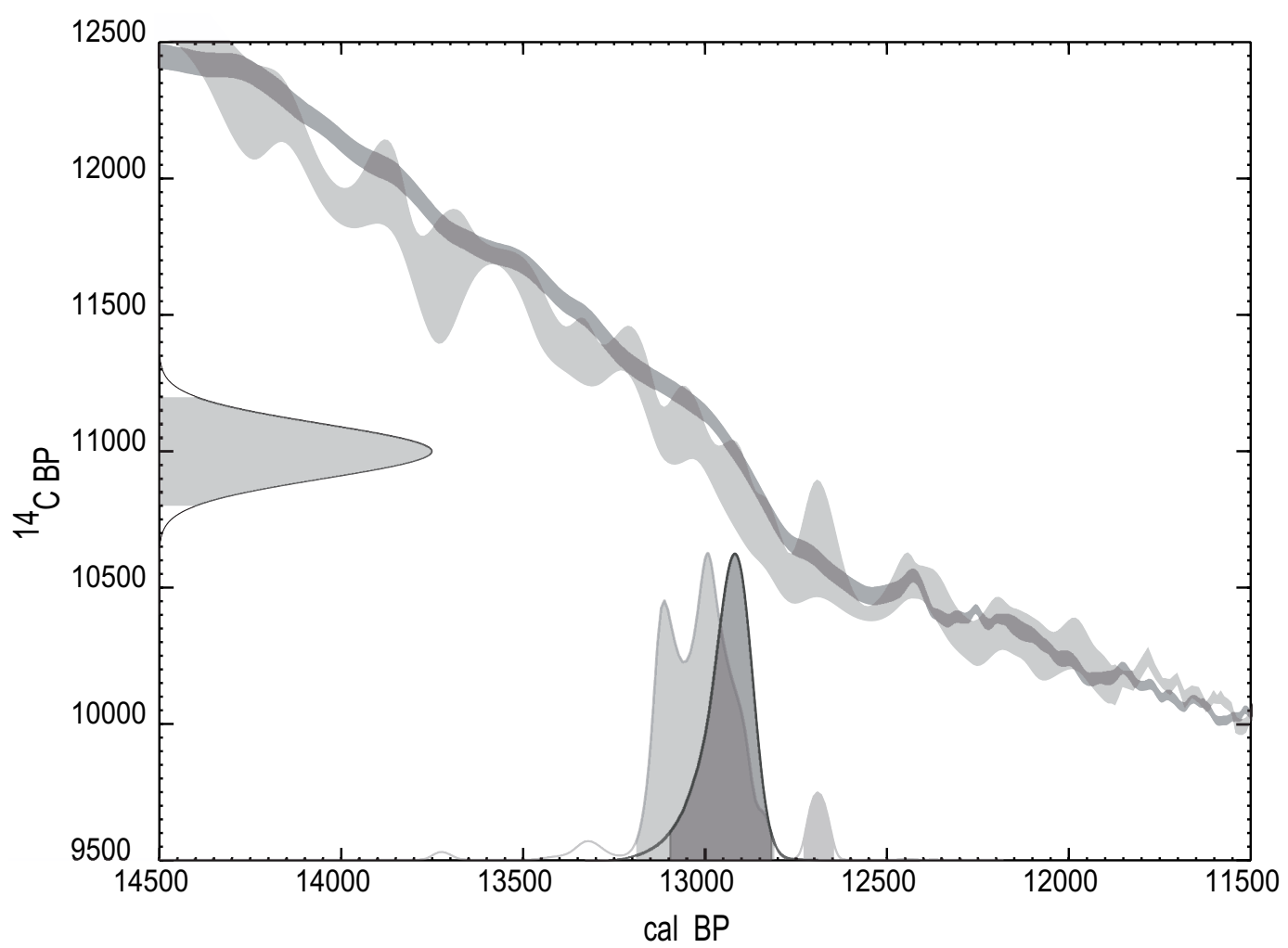

Figure 4 Calibrated probability distributions for a hypothetical ${ }^{14} \mathrm{C}$ age of $11,000 \pm 100{ }^{14} \mathrm{C}$ BP calibrated with IntCa198 (light gray) and IntCal04 (dark gray) showing 95\% cal age ranges.

The entire IntCal04 data set and calibration curve is plotted in 2000-yr sections for use in estimating calibrated age ranges (Appendix, Figure A1-A13). Note that there are still gaps of greater than $700 \mathrm{yr}$ in the calibration data at 16-17 cal kyr BP, 20.6-21.6 cal kyr BP, and 23.8-24.6 cal kyr BP. ${ }^{14} \mathrm{C}$ age calibrations in these sections will therefore be less precise; this is reflected in the increased uncertainty on the curve in these regions.

\section{ACKNOWLEDGMENTS}

We wish to thank the Leverhulme Trust for support for the IntCal workshops and a portion of the work on data compilation. We also thank Prof Gerry McCormac of the Queen's University Belfast Radiocarbon Lab and Prof John Hayes, NOSAMS, for generous support and hospitality at the meetings. A portion of this work was performed under National Science Foundation grant ATM0407554. A portion of this work was performed under the auspices of the U S Department of Energy by the University of California, Lawrence Livermore National Laboratory under Contract No. W7405-Eng-48.

Caitlin Buck acknowledges, with gratitude, the support and encouragement of her colleagues during a period of ill health while working on this project. In addition, she wishes to thank the staff of the Access to Work team in Sheffield and the Support Worker whom they funded, Sammy Rashid, without whose patience and practical and intellectual input she could not have completed her contribution to this work. 


\section{REFERENCES}

Bard E, Arnold M, Hamelin B, Tisnerat-Laborde N, Cabioch G. 1998. Radiocarbon calibration by means of mass spectrometric ${ }^{230} \mathrm{Th} /{ }^{234} \mathrm{U}$ and ${ }^{14} \mathrm{C}$ ages of corals: an updated database including samples from Barbados, Mururoa and Tahiti. Radiocarbon 40(3):108592.

Bard E, Ménot-Combes G, Rosek F. 2004. Present status of radiocarbon calibration and comparison records based on Polynesian corals and Iberian Margin sediments. Radiocarbon, this issue.

Beck JW, Richards DA, Edwards RL, Silverman BW, Smart PL, Donahue DJ, Herrera-Osterheld S, Burr GS, Calsoyas L, Jull AJT, Biddulph D. 2001. Extremely large variations of atmospheric ${ }^{14} \mathrm{C}$ concentration during the last glacial period. Science 292:2453-8

Becker B, Kromer B. 1986. Extension of the Holocene dendrochronology by the Preboreal pine series, 8800 to 10,100 BP. Radiocarbon 28(2B):961-7.

Braziunas TF, Fung IY, Stuiver M. 1995. The preindustrial atmospheric ${ }^{14} \mathrm{CO}_{2}$ latitudinal gradient as related to exchanges among atmospheric, oceanic, and terrestrial reservoirs. Global Biogeochemical Cycles 9:56584.

Buck CE, Blackwell PG. 2004. Formal statistical models for estimating radiocarbon calibration curves. Radiocarbon, this issue.

Burr GS, Galang C, Taylor FW, Gallup C, Edwards RL, Cutler KB, Quirk B. 2004. Radiocarbon results from a 13-kyr BP coral from the Huon Peninsula, Papua New Guinea. Radiocarbon, this issue.

Cutler KB, Gray SC, Burr GS, Edwards RL, Taylor FW, Cabioch G, Beck JW, Récy J, Cheng H, Moore J. 2004. Radiocarbon calibration to $50 \mathrm{kyr}$ BP with paired ${ }^{14} \mathrm{C}$ and ${ }^{230} \mathrm{Th}$ dating of corals from Vanuatu and Papua New Guinea. Radiocarbon, this issue.

Damon PE, Burr G, Peristykh AN, Jacoby GC, Darrigo RD. 1996. Regional radiocarbon effect due to thawing of frozen earth. Radiocarbon 38(3):597-602.

de Jong AFM, Becker B, Mook WG. 1986. High-precision calibration of the radiocarbon time scale, 39303230 cal BC. Radiocarbon 28(2B):939-41.

de Jong AFM, Becker B, Mook WG. 1989. Corrected calibration of the radiocarbon time scale. Radiocarbon 31(2):201-10.

Dellinger F, Kutschera W, Steier P, Wild EM, Nicolussi K, Scheißling P. 2004. A ${ }^{14} \mathrm{C}$ calibration with AMS from 3500 to $3000 \mathrm{BC}$, derived from a new high-elevation stone-pine tree-ring chronology. Radiocarbon 46(2):969-78

Fairbanks RG, Mortlock RA, Chiu T-C, Guilderson TP, Cao L, Kaplan A, Bloom A. Forthcoming. Marine radiocarbon calibration curve spanning 7000 to 50,000 years BP based on paired ${ }^{230} \mathrm{Th} /{ }^{234} \mathrm{U} /{ }^{238} \mathrm{U}$ and ${ }^{14} \mathrm{C}$ dates on pristine corals. Quaternary Science Reviews.

Friedrich M, Remmele S, Kromer B, Hofmann J, Spurk
M, Kaiser KF, Orcel C, Küppers M. 2004. The 12,460year Hohenheim oak and pine tree-ring chronology from central Europe- a unique annual record for radiocarbon calibration and paleoenvironment reconstructions. Radiocarbon, this issue

Hogg AG, McCormac FG, Higham TFG, Reimer PJ, Baillie MGL, Palmer JG. 2002. High-precision radiocarbon measurements of contemporaneous tree-ring dated wood from the British Isles and New Zealand: AD 1850-950. Radiocarbon 44(3):633-40.

Hoper ST, McCormac FG, Hogg AG, Higham TFG, Head MJ. 1998. Evaluation of wood pretreatments on oak and cedar. Radiocarbon 40(1):45-50.

Hughen KA, Baillie MGL, Bard E, Bayliss A, Beck JW, Bertrand CJH, Blackwell PG, Buck CE, Burr GS, Cutler KB, Damon PE, Edwards RL, Fairbanks RG, Friedrich M, Guilderson TP, Kromer B, McCormac FG, Manning SW, Bronk Ramsey C, Reimer PJ, Reimer RW, Remmele S, Southon JR, Stuiver M, Talamo $\mathrm{S}$, Taylor FW, van der Plicht J, Weyhenmeyer CE. 2004a. Marine 04 marine radiocarbon age calibration, 26-0 kyr BP. Radiocarbon, this issue a.

Hughen KA, Southon JR, Bertrand CJH, Frantz B, Zermeño P. 2004b. Cariaco Basin calibration update: revisions to calendar and ${ }^{14} \mathrm{C}$ chronologies for core PL07-58PC. Radiocarbon, this issue b.

Hughen KA, Lehman S, Southon J, Overpeck J, Marchal O, Herring C, Turnbull J. 2004. ${ }^{14} \mathrm{C}$ activity and global carbon cycle changes over the past 50,000 years. Science 303(5655):202-7.

Hughen KA, Southon JR, Lehman SJ, Overpeck JT. 2000. Synchronous radiocarbon and climate shifts during the last deglaciation. Science 290:1951-4.

Kitagawa H, van der Plicht J. 2000. Atmospheric radiocarbon calibration beyond $11,900 \mathrm{cal}$ BP from Lake Suigetsu laminated sediments. Radiocarbon 42(3): 369-80.

Kromer B, Ambers J, Baillie MGL, Damon PE, Hesshaimer V, Hofmann J, Jöris O, Levin I, Manning SW, McCormac FG, van der Plicht J, Spurk M, Stuiver M, Weninger B. 1996. Report: summary of the workshop "Aspects of High-Precision Radiocarbon Calibration." Radiocarbon 38(3):607-10.

Kromer B, Manning SW, Kuniholm PI, Newton MW, Spurk M, Levin I. 2001. Regional ${ }^{14} \mathrm{CO}_{2}$ gradients in the troposphere: magnitude, mechanisms and consequences. Science 294:2529-32.

Kromer B, Rhein M, Bruns M, Schochfischer H, Münnich KO, Stuiver M, Becker B. 1986. Radiocarbon calibration data for the 6th to the 8th millennia BC. Radiocarbon 28(2B):954-60.

Linick TW, Long A, Damon PE, Ferguson CW. 1986. High-precision radiocarbon dating of bristlecone pine from 6554 to 5350 BC. Radiocarbon 28(2B):943-53.

Manning SW, Barbetti M, Kromer B, Kuniholm PI, Levin I, Newton MW, Reimer PJ. 2002. No systematic 
early bias to Mediterranean ${ }^{14} \mathrm{C}$ ages: radiocarbon measurements from tree-ring and air samples provide tight limits to age offsets. Radiocarbon 44(3):739-54.

Manning SW, Kromer B, Kuniholm PI, Newton MW. 2001. Anatolian tree rings and a new chronology for the east Mediterranean Bronze-Iron Ages. Science 294:2532-5.

McCormac FG, Bayliss A, Baillie MGL. 2004. Radiocarbon calibration in the Anglo-Saxon period: AD 495725. Radiocarbon, this issue.

McCormac FG, Reimer PJ, Hogg AG, Higham TFG, Baillie MGL, Palmer J, Stuiver M. 2002. Calibration of the radiocarbon time scale for the Southern Hemisphere: AD 1850-950. Radiocarbon 44(3):641-51.

Mitchell JJ, Dzerdzeevskii M, Flohn H, Hofmeyr WL, Lamb HH. 1966. Climatic Change. Geneva: World Meterological Organization. $79 \mathrm{p}$.

Pearson GW, Becker B, Qua F. 1993. High-precision ${ }^{14} \mathrm{C}$ measurement of German and Irish oaks to show the natural ${ }^{14} \mathrm{C}$ variations from 7890 to $5000 \mathrm{BC}$. Radiocarbon 35(1):93-104.

Pearson GW, Pilcher JR, Baillie MGL, Corbett DM, Qua F. 1986. High-precision ${ }^{14} \mathrm{C}$ measurement of Irish oaks to show the natural ${ }^{14} \mathrm{C}$ variations from $\mathrm{AD} 1840$ to 5210 BC. Radiocarbon 28(2B):911-34.

Pilcher JR, Baillie MGL, Schmidt B, Becker B. 1984. A 7,272-year tree-ring chronology for western Europe. Nature 312:150-2.

Reimer PJ, Hughen KA, Guilderson TP, McCormac FG, Baillie MGL, Bard E, Barratt P, Beck JW, Brown DM, Buck CE, Damon PE, Friedrich M, Kromer B, Ramsey CB, Reimer RW, Remmele S, Southon JR, Stuiver M, van der Plicht J. 2002. Preliminary report of the first workshop of the IntCal04 Radiocarbon Calibration/Comparison Working Group. Radiocarbon 44(3): 653-61.

Sakamoto M, Imamura M, van der Plicht J, Mitsutani T, Sahara M. 2003. Radiocarbon calibration for Japanese wood samples. Radiocarbon 45(1):81-9.

Schramm A, Stein M, Goldstein SL. 2000. Calibration of the ${ }^{14} \mathrm{C}$ time scale to $>40$ ka by ${ }^{234} \mathrm{U}^{230} \mathrm{Th}$ dating of Lake Lisan sediments (last glacial Dead Sea). Earth and Planetary Science Letters 175:27-40.

Spurk M, Friedrich M, Hofmann J, Remmele S, Frenzel B, Leuschner HH, Kromer B. 1998. Revisions and extension of the Hohenheim oak and pine chronologies: new evidence about the timing of the Younger Dryas/ Preboreal transition. Radiocarbon 40(3):1107-16.

Stuiver M. 1982. A high-precision calibration of the AD radiocarbon time scale. Radiocarbon 24(1):1-26.
Stuiver M, Braziunas TF. 1993. Modeling atmospheric ${ }^{14} \mathrm{C}$ influences and ${ }^{14} \mathrm{C}$ ages of marine samples to 10,000 BC. Radiocarbon 35(1):137-89.

Stuiver M, Pearson GW, Braziunas T. 1986. Radiocarbon age calibration of marine samples back to $9000 \mathrm{cal} \mathrm{yr}$ BP. Radiocarbon 28(2B):980-1021.

Stuiver M, Quay PD. 1981. A 1600-year-long record of solar change derived from atmospheric ${ }^{14} \mathrm{C}$ levels. Solar Physics 74:479-81.

Stuiver M, Reimer PJ, Bard E, Beck JW, Burr GS, Hughen KA, Kromer B, McCormac G, van der Plicht J, Spurk M. 1998a. IntCa198 radiocarbon age calibration, 24,000-0 cal BP. Radiocarbon 40(3):1041-83.

Stuiver M, Reimer PJ, Braziunas TF. 1998b. High-precision radiocarbon age calibration for terrestrial and marine samples. Radiocarbon 40(3):1127-51.

van der Borg K, Stein M, de Jong AFM, Waldmann N, Goldstein S. 2004. Near-zero $\Delta^{14} \mathrm{C}$ values at $32 \mathrm{kyr}$ cal $\mathrm{BP}$ observed in the high-resolution ${ }^{14} \mathrm{C}$ record from $\mathrm{U}$ Th dated sediment of Lake Lisan. Radiocarbon 46(2): 785-96.

van der Plicht J, Beck JW, Bard E, Baillie MGL, Blackwell PG, Buck CE, Friedrich M, Guilderson TP, Hughen KA, Kromer B, McCormac FG, Bronk Ramsey C, Reimer PJ, Reimer RW, Remmele S, Richards DA, Southon JR, Stuiver M, Weyhenmeyer CE. 2004. NotCal04-Comparison/Calibration ${ }^{14} \mathrm{C}$ records 2650 cal kyr BP. Radiocarbon, this issue.

van Kreveld S, Sarntheim M, Erlenkeuser H, Grootes PM, Jung S, Nadeau MJ, Pflaumann U, Voelker A. 2000. Potential links between surging ice sheets, circulation changes, and the Dansgaard-Oeschger cycles in the Irminger Sea, 60-18 kyr. Paleoceanography 15: 425-42.

Voelker AHL, Grootes PM, Nadeau MJ, Sarntheim M. 2000. Radiocarbon levels in the Iceland Sea from 25$53 \mathrm{kyr}$ and their link to the Earth's magnetic field intensity. Radiocarbon 42(3):437-52.

Vogel JC, Fuls A, Visser E, Becker B. 1986. Radiocarbon fluctuations during the $3 \mathrm{rd}$ millennium BC. Radiocarbon 28(2B): $935-8$.

Vogel JC, van der Plicht J. 1993. Calibration curve for short-lived samples, 1900-3900 BC. Radiocarbon 35(1):87-91.

Weyhenmeyer CE, Burns S, Fleitmann D, Kramers JD, Matter A, Waber HN, Reimer PJ. 2003. Changes in atmospheric ${ }^{14} \mathrm{C}$ between 55 and $42 \mathrm{ky}$ BP recorded in a stalagmite from Socotra Island, Indian Ocean. EOS Transactions AGU 84 (46): Fall Meeting Supplement Abstract PP32B-0298. 


\section{APPENDIX}

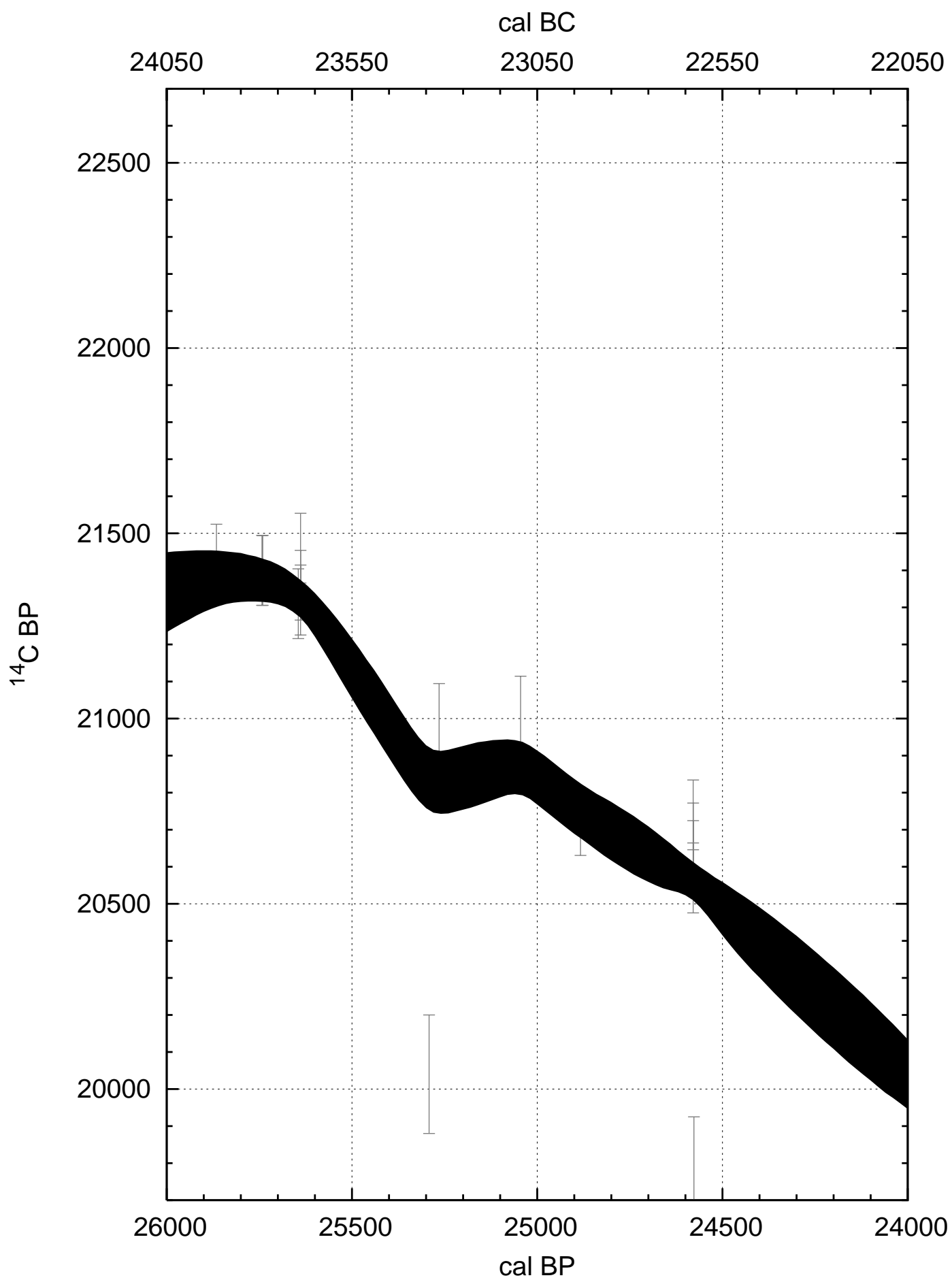

Figure A1 The IntCal04 terrestrial calibration curve (1-standard deviation envelope) and data with 1-standard deviation error bars in ${ }^{14} \mathrm{C}$ increased by the laboratory error multipliers described in the text. The uncertainty in the calendar ages is not shown, but is taken into account in the random walk model. 


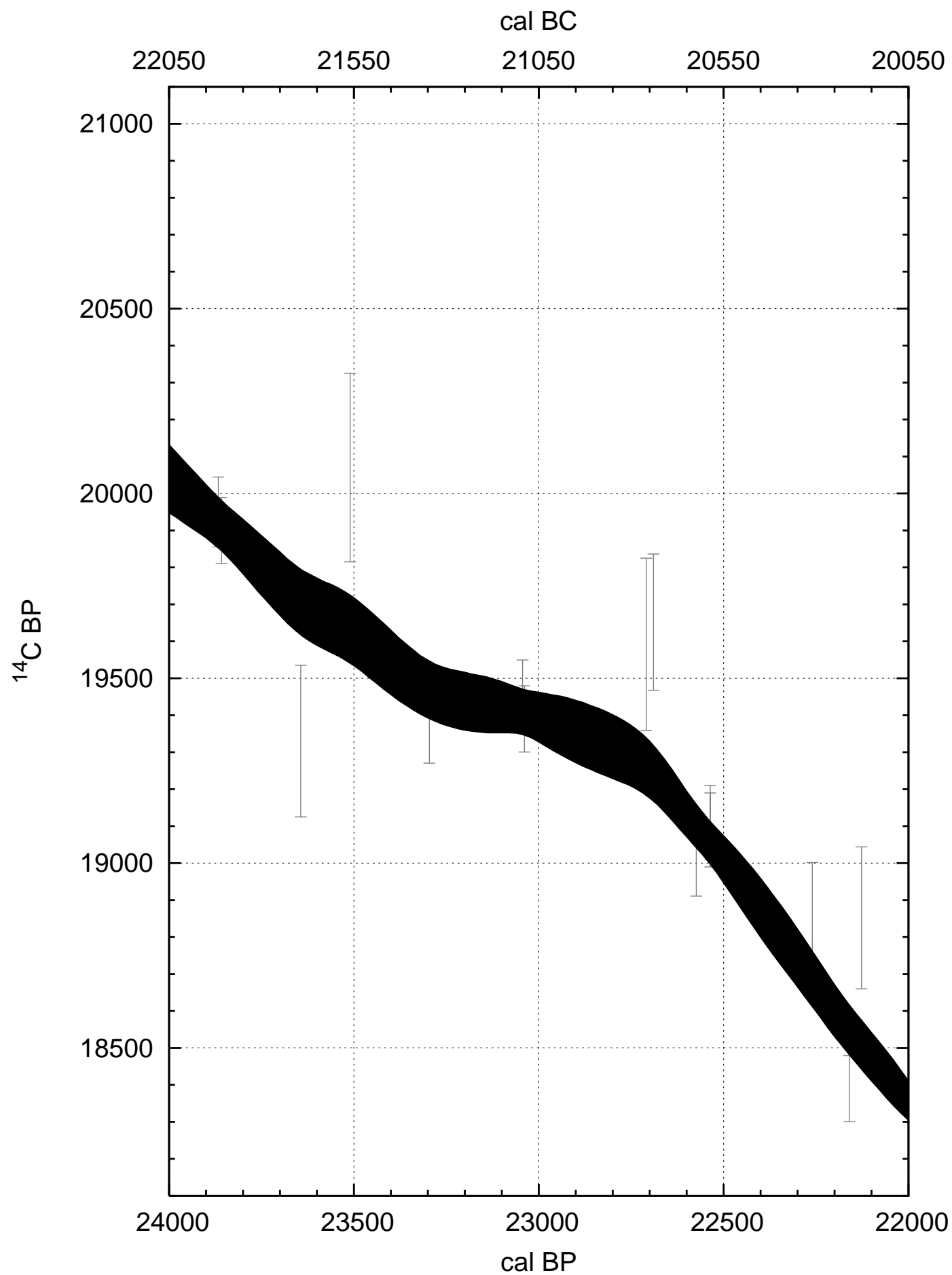

Figure A2 The IntCa104 terrestrial calibration curve (1-standard deviation envelope) and data with 1-standard deviation error bars in ${ }^{14} \mathrm{C}$ increased by the laboratory error multipliers described in the text. The uncertainty in the calendar ages is not shown, but is taken into account in the random walk model. 


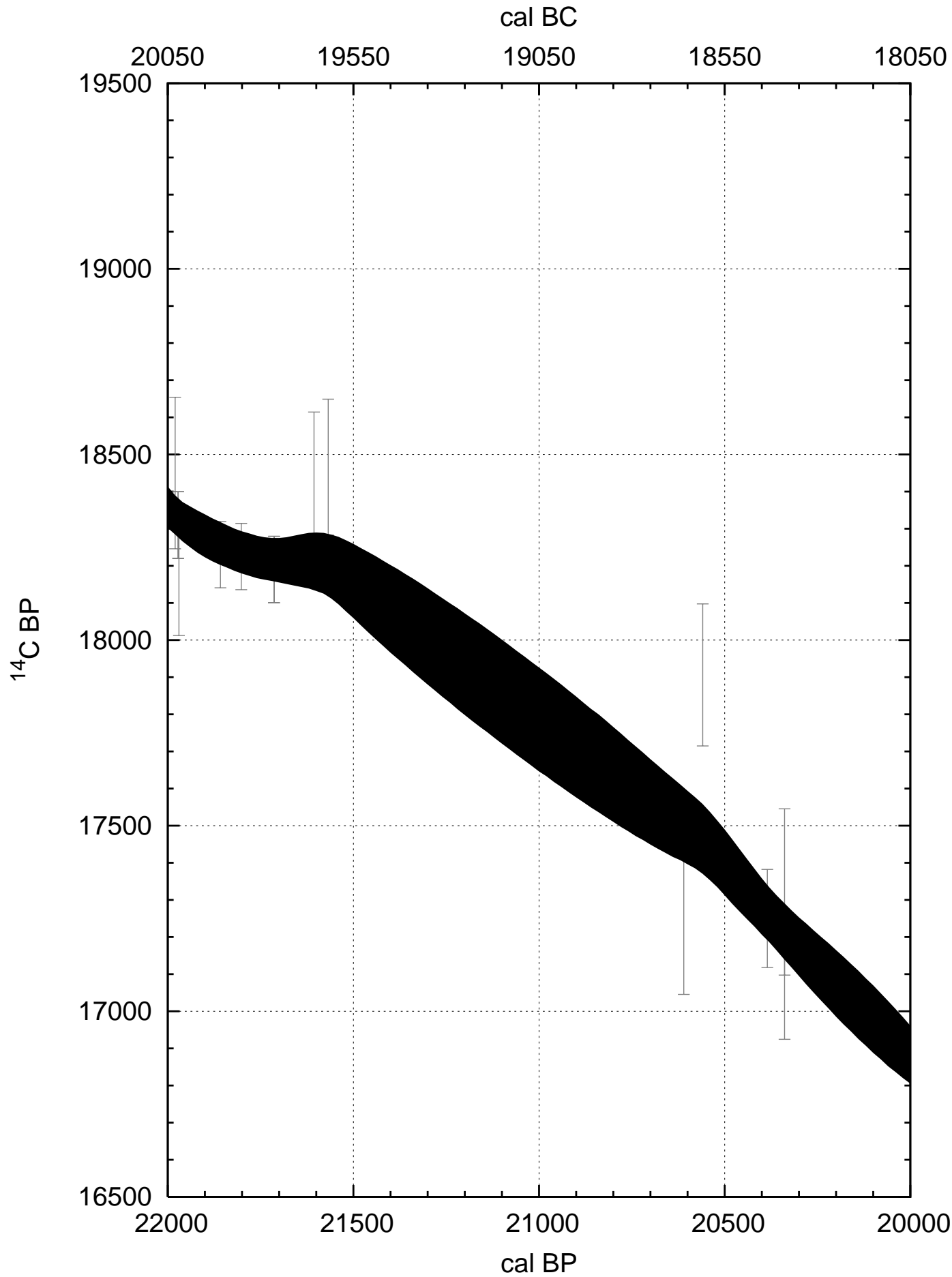

Figure A3 The IntCal04 terrestrial calibration curve (1-standard deviation envelope) and data with 1-standard deviation error bars in ${ }^{14} \mathrm{C}$ increased by the laboratory error multipliers described in the text. The uncertainty in the calendar ages is not shown, but is taken into account in the random walk model. 


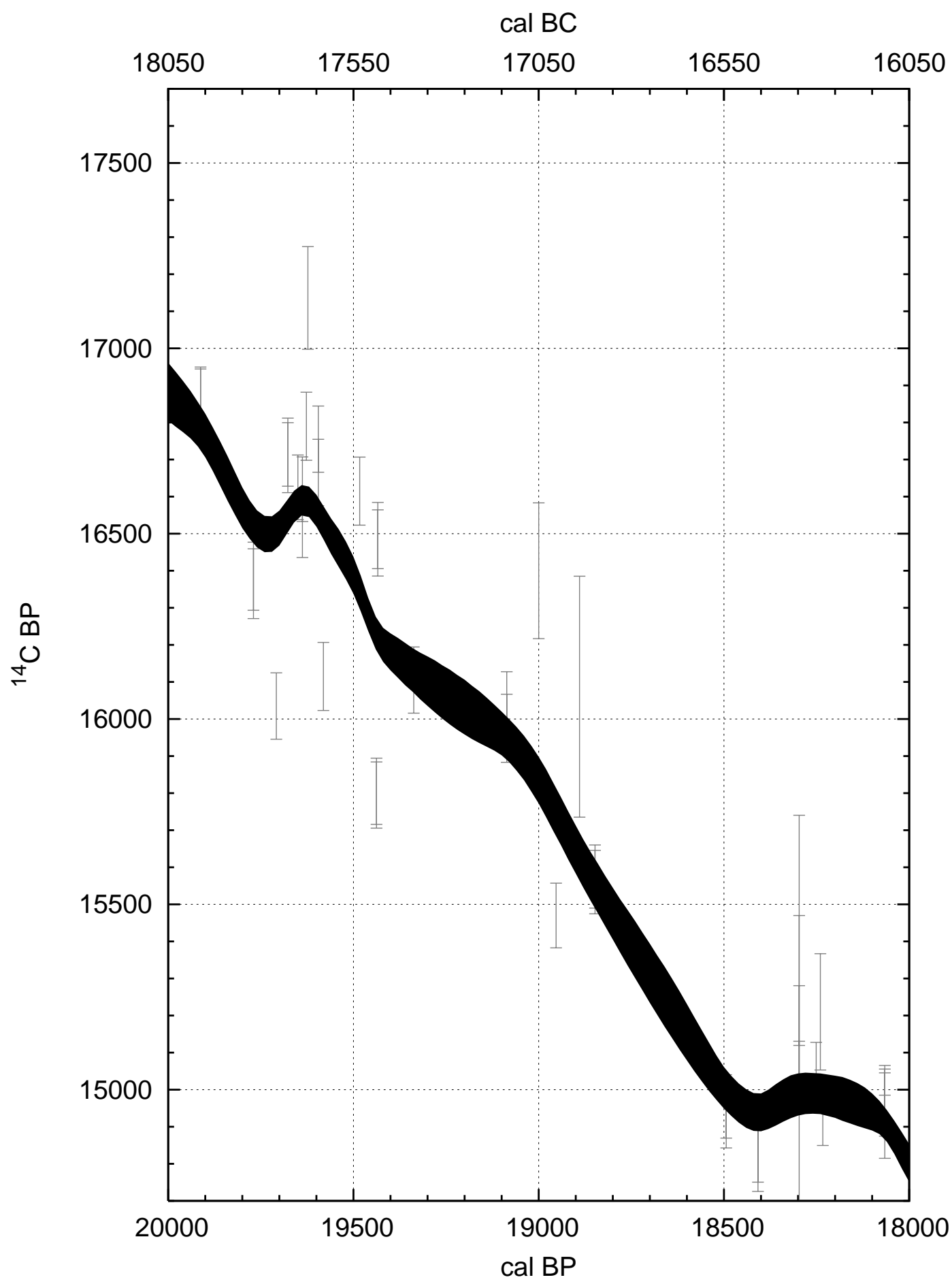

Figure A4 The IntCal04 terrestrial calibration curve (1-standard deviation envelope) and data with 1-standard deviation error bars in ${ }^{14} \mathrm{C}$ increased by the laboratory error multipliers described in the text. The uncertainty in the calendar ages is not shown, but is taken into account in the random walk model. 


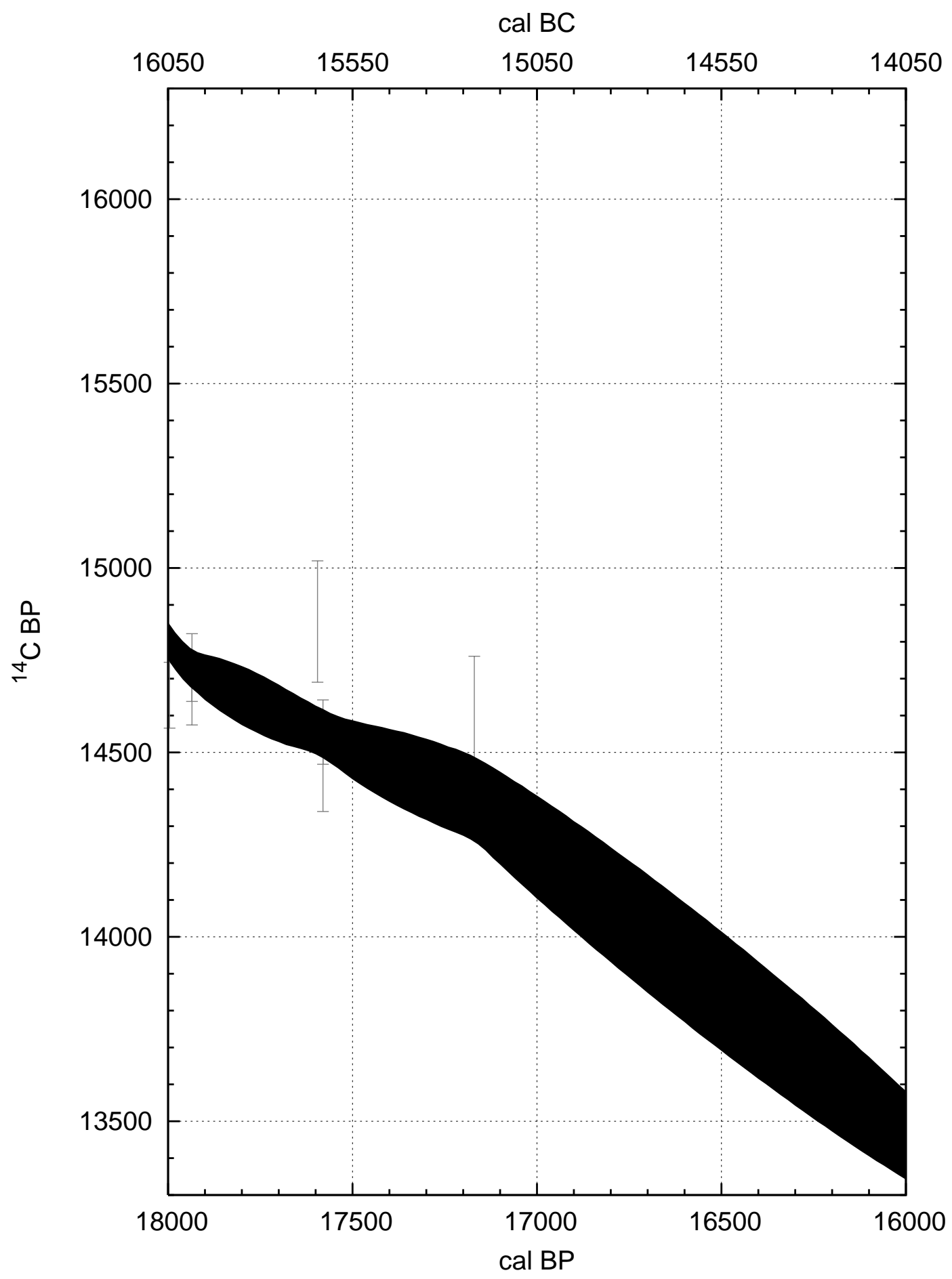

Figure A5 The IntCal04 terrestrial calibration curve (1-standard deviation envelope) and data with 1-standard deviation error bars in ${ }^{14} \mathrm{C}$ increased by the laboratory error multipliers described in the text. The uncertainty in the calendar ages is not shown, but is taken into account in the random walk model. 


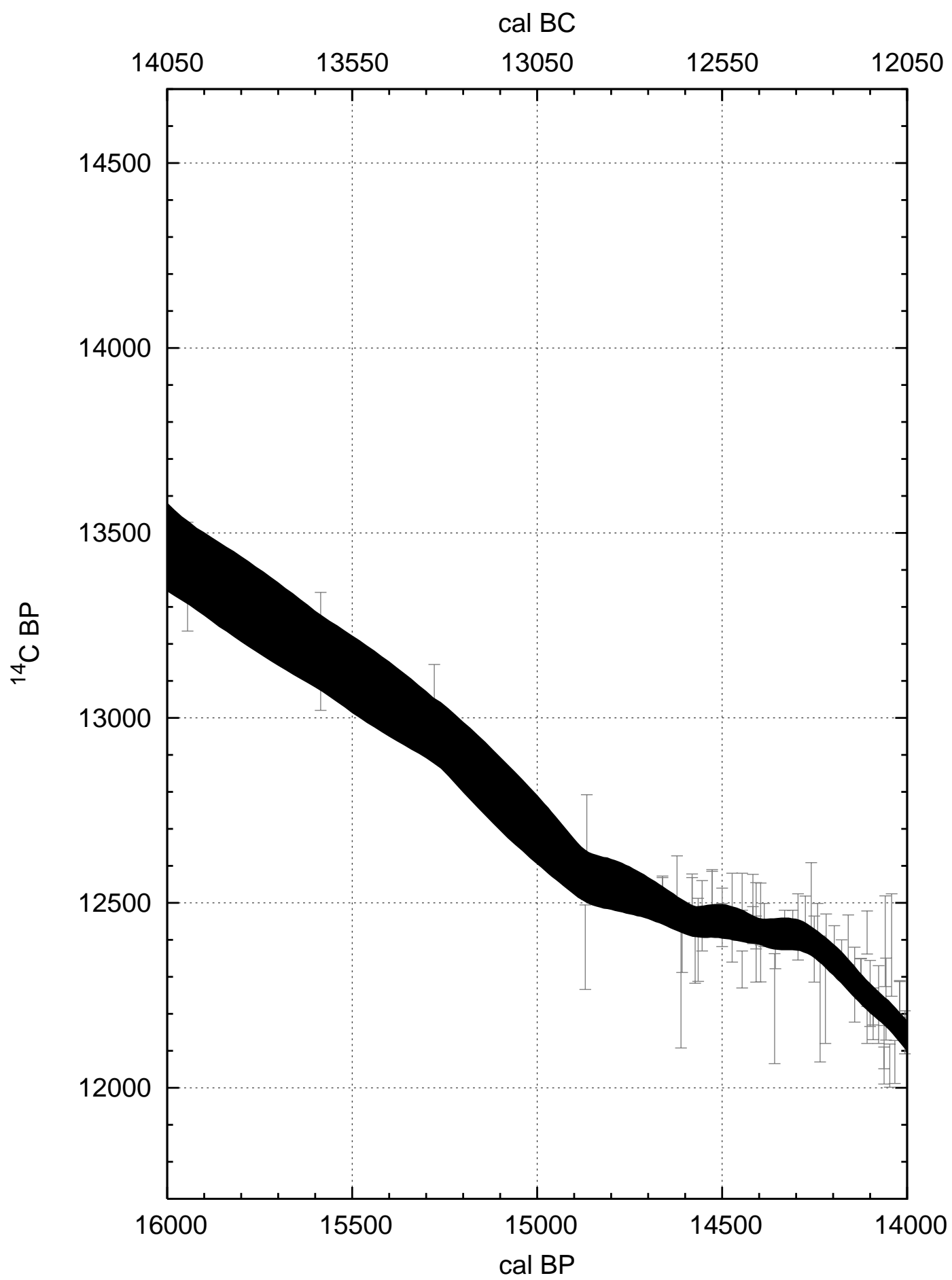

Figure A6 The IntCal04 terrestrial calibration curve (1-standard deviation envelope) and data with 1-standard deviation error bars in ${ }^{14} \mathrm{C}$ increased by the laboratory error multipliers described in the text. The uncertainty in the calendar ages is not shown, but is taken into account in the random walk model. 


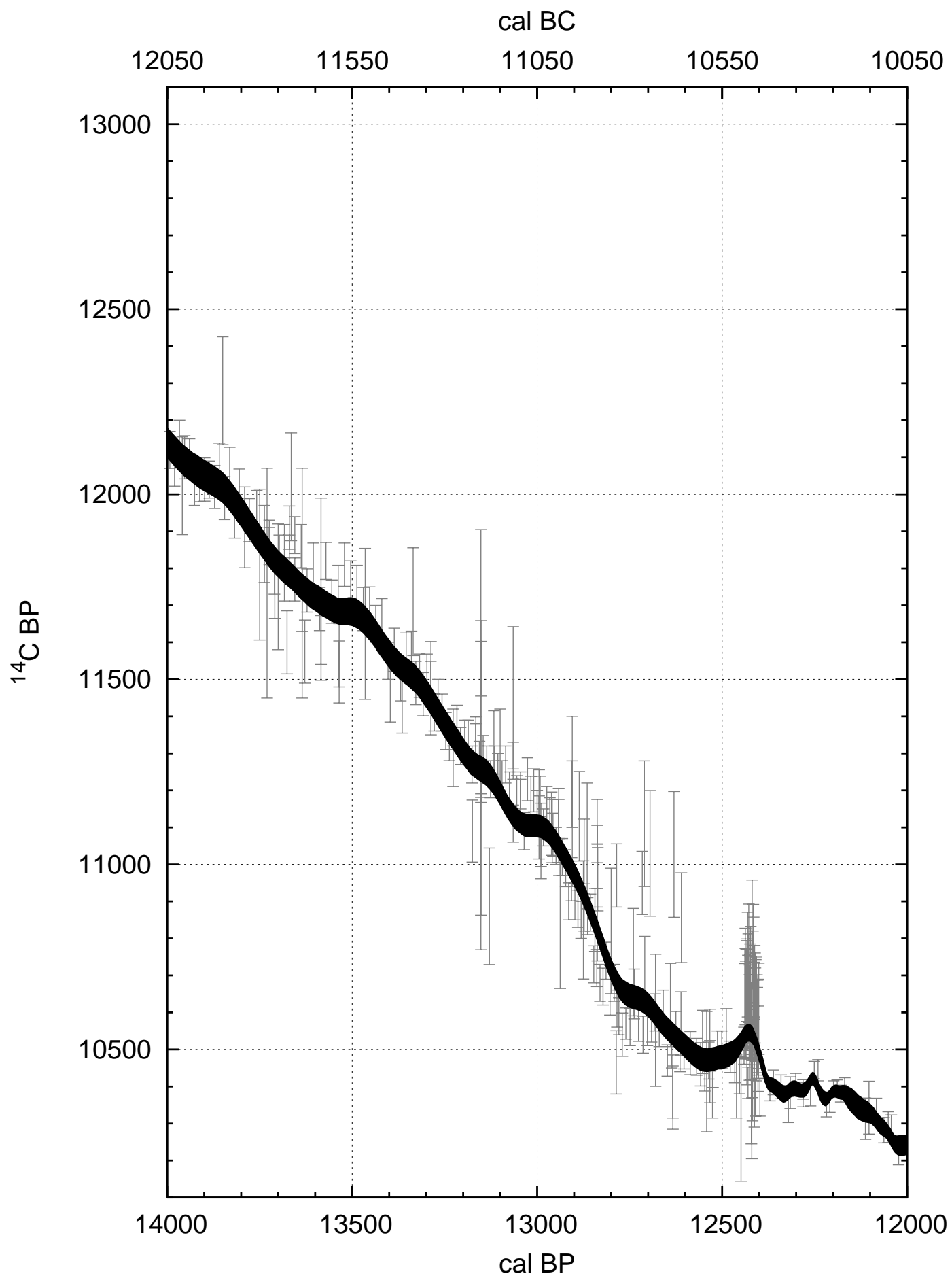

Figure A7 The IntCa104 terrestrial calibration curve (1-standard deviation envelope) and data with 1-standard deviation error bars in ${ }^{14} \mathrm{C}$ increased by the laboratory error multipliers described in the text. The uncertainty in the calendar ages is not shown, but is taken into account in the random walk model. 


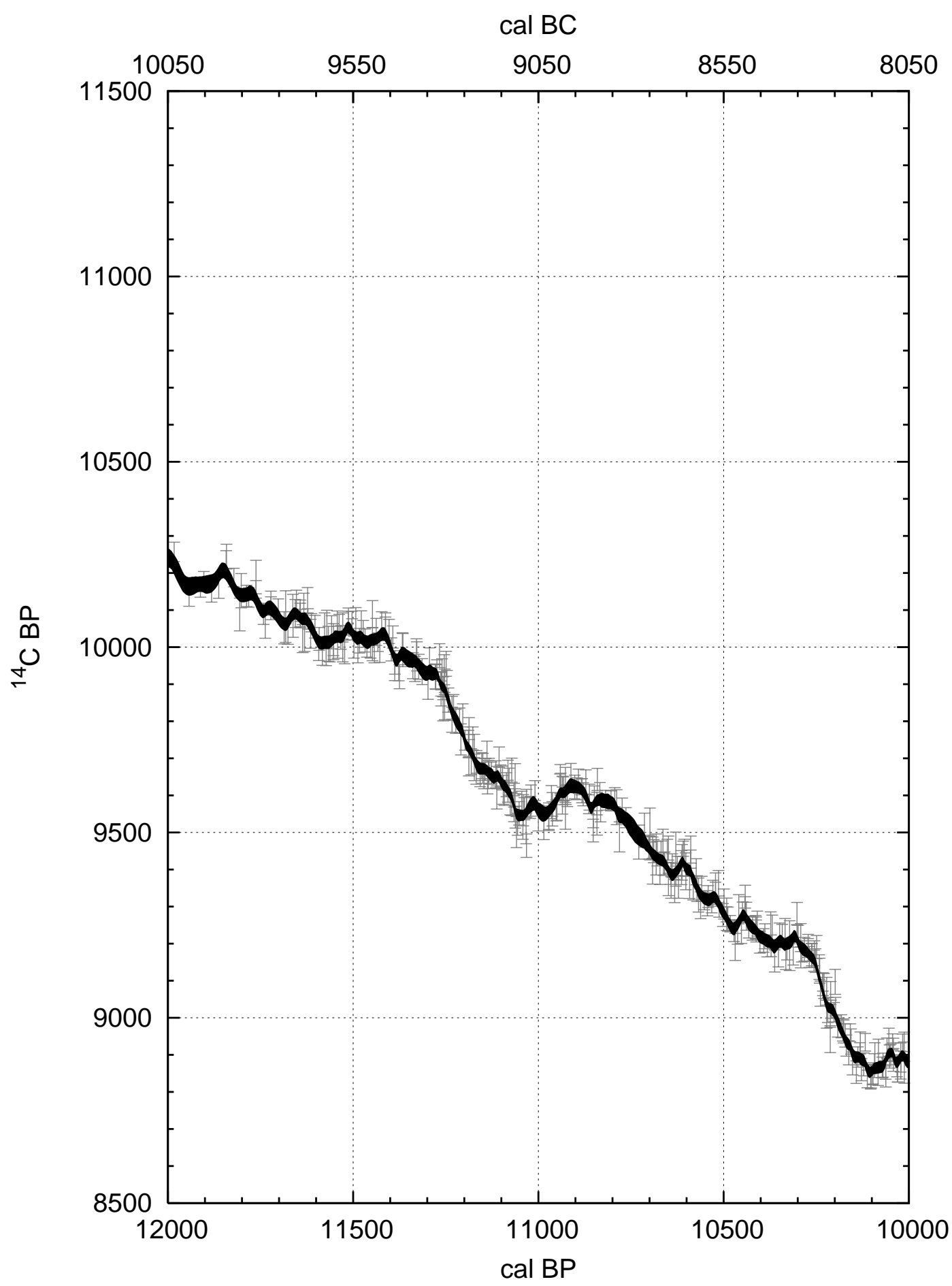

Figure A8 The IntCa104 terrestrial calibration curve (1-standard deviation envelope) and data with 1-standard deviation error bars in ${ }^{14} \mathrm{C}$ increased by the laboratory error multipliers described in the text. The uncertainty in the calendar ages is not shown, but is taken into account in the random walk model. 


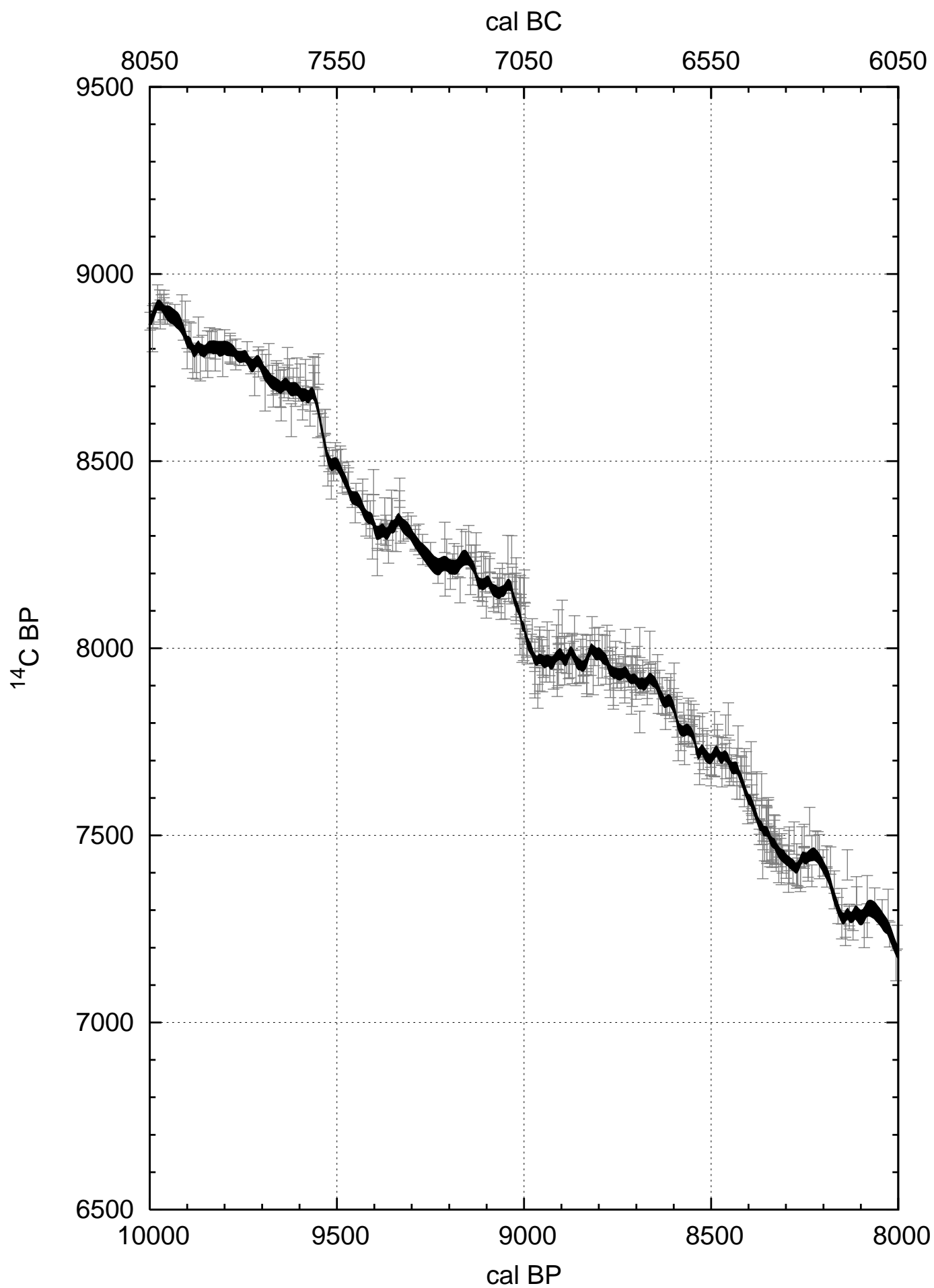

Figure A9 The IntCal04 terrestrial calibration curve (1-standard deviation envelope) and data with 1-standard deviation error bars in ${ }^{14} \mathrm{C}$ increased by the laboratory error multipliers described in the text. The uncertainty in the calendar ages is not shown, but is taken into account in the random walk model. 


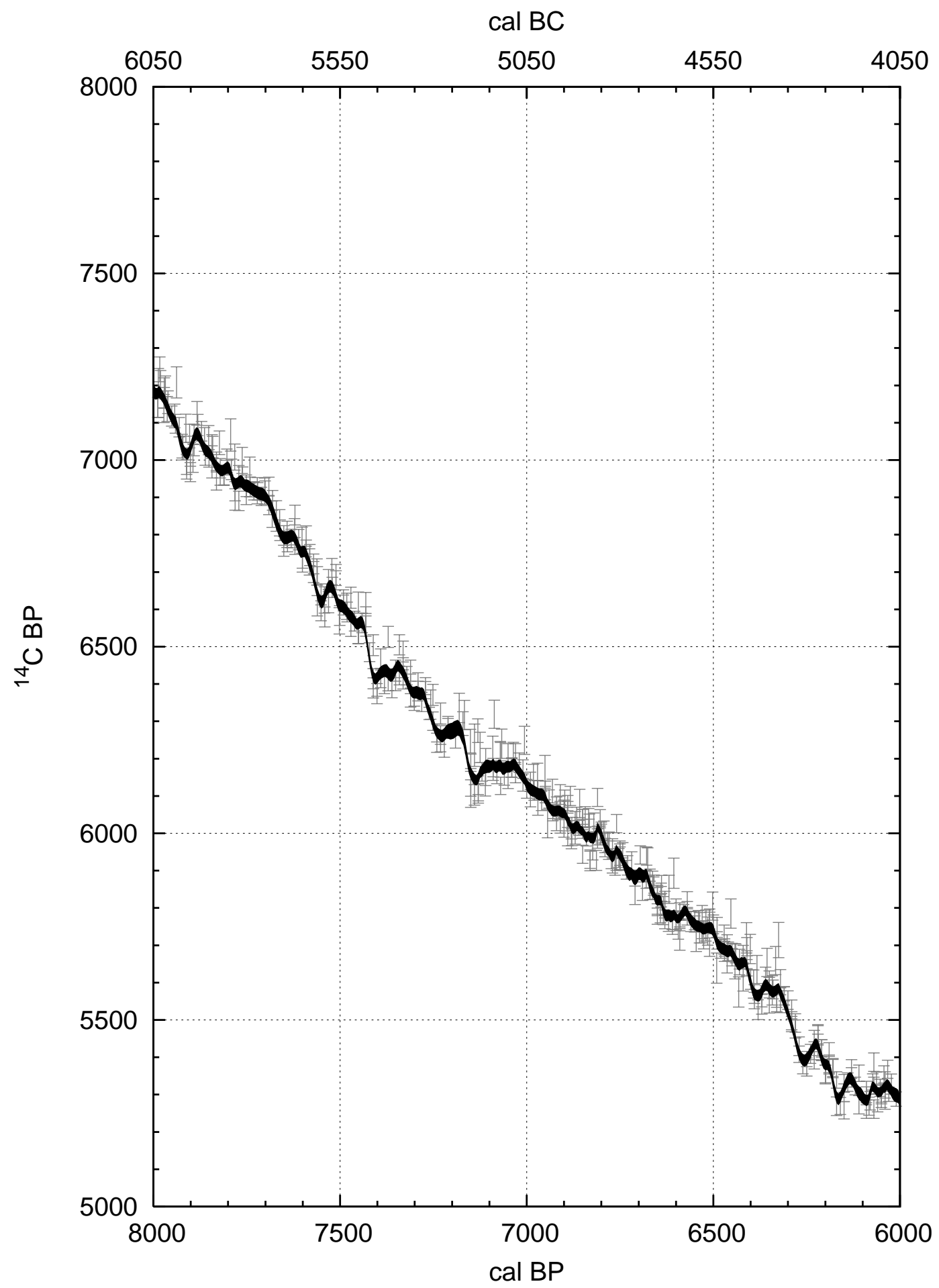

Figure A10 The IntCa104 terrestrial calibration curve (1-standard deviation envelope) and data with 1-standard deviation error bars in ${ }^{14} \mathrm{C}$ increased by the laboratory error multipliers described in the text. The uncertainty in the calendar ages is not shown, but is taken into account in the random walk model. 


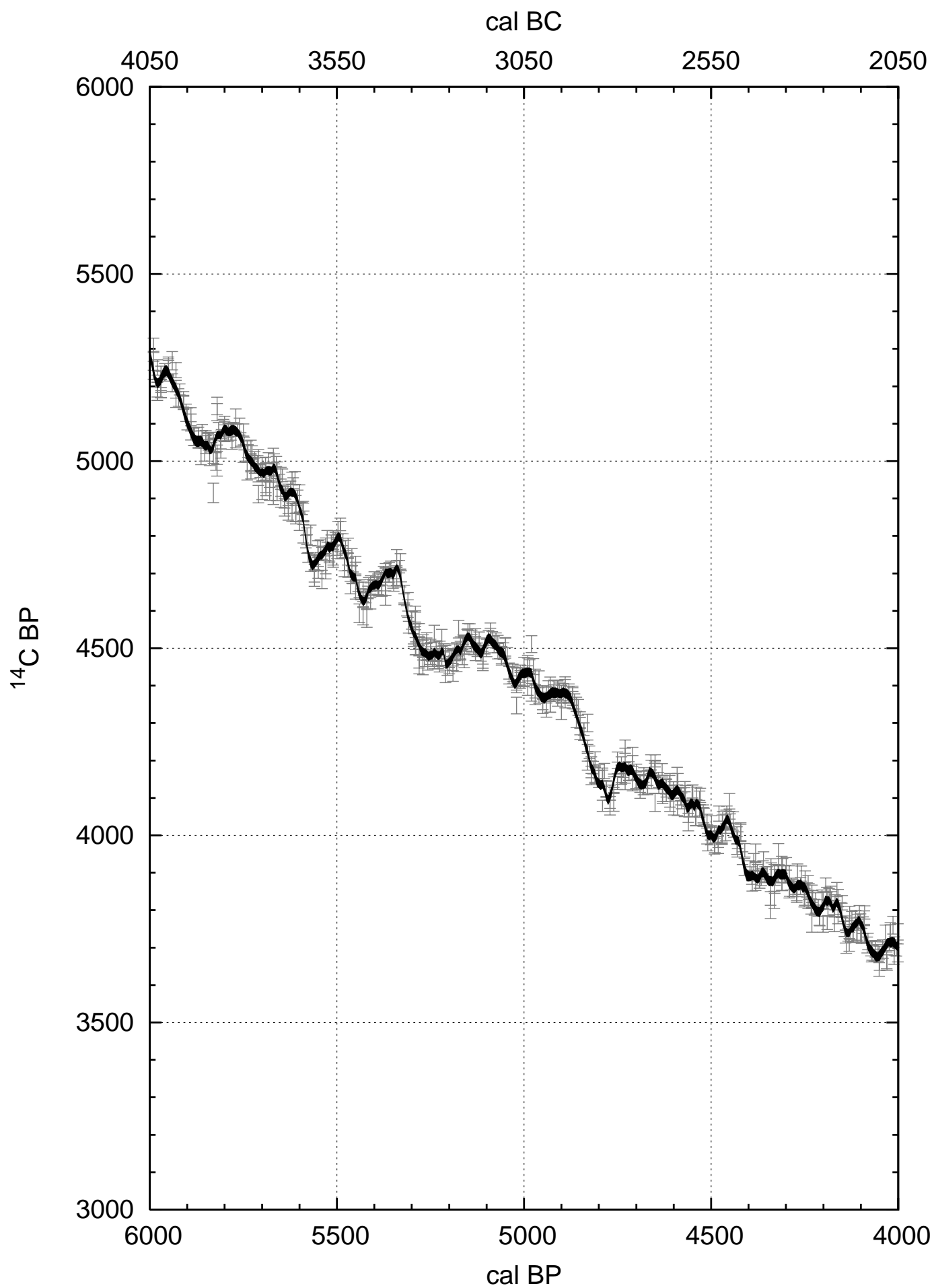

Figure A11 The IntCa104 terrestrial calibration curve (1-standard deviation envelope) and data with 1-standard deviation error bars in ${ }^{14} \mathrm{C}$ increased by the laboratory error multipliers described in the text. The uncertainty in the calendar ages is not shown, but is taken into account in the random walk model. 


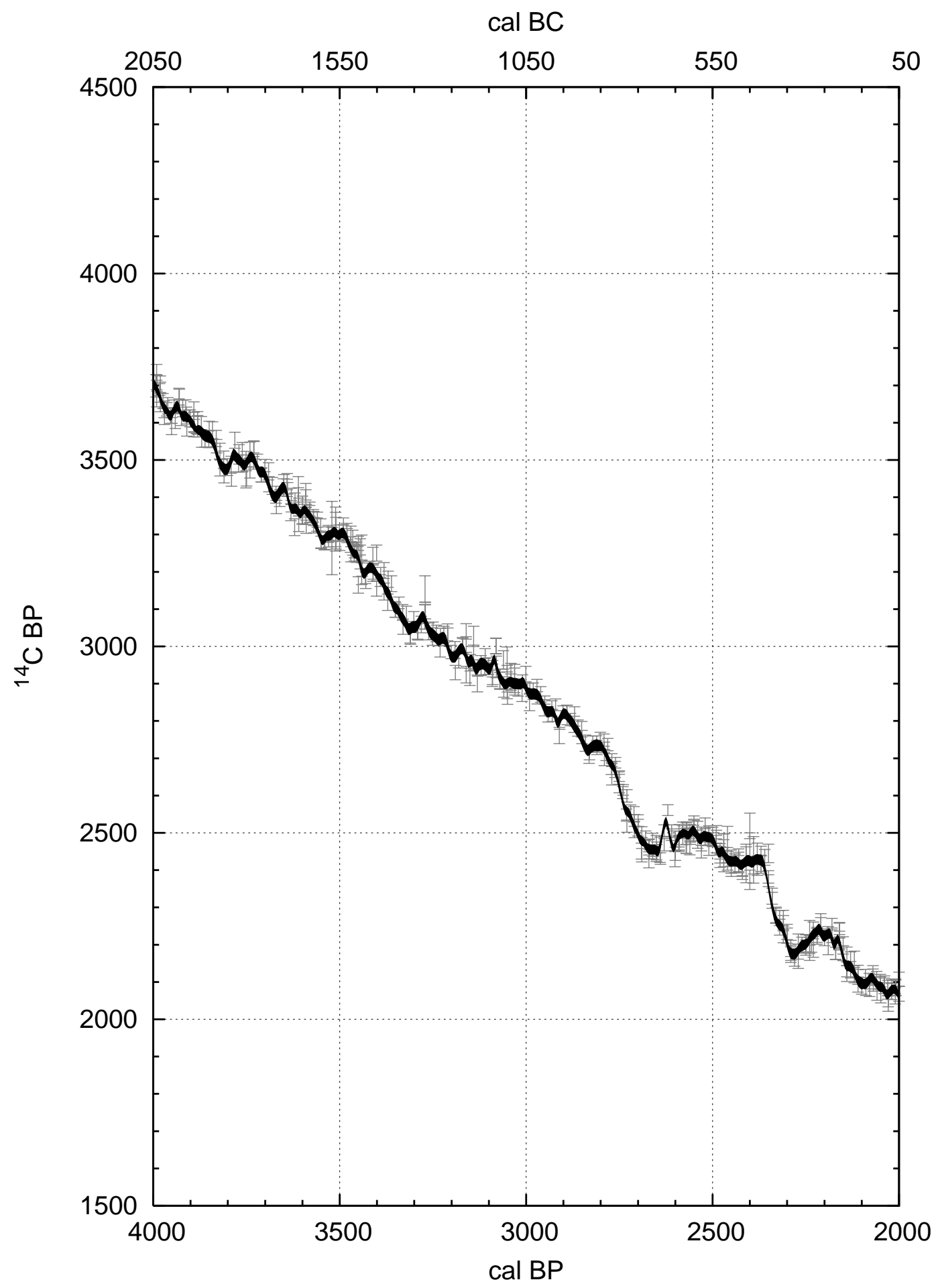

Figure A12 The IntCa104 terrestrial calibration curve (1-standard deviation envelope) and data with 1-standard deviation error bars in ${ }^{14} \mathrm{C}$ increased by the laboratory error multipliers described in the text. The uncertainty in the calendar ages is not shown, but is taken into account in the random walk model. 


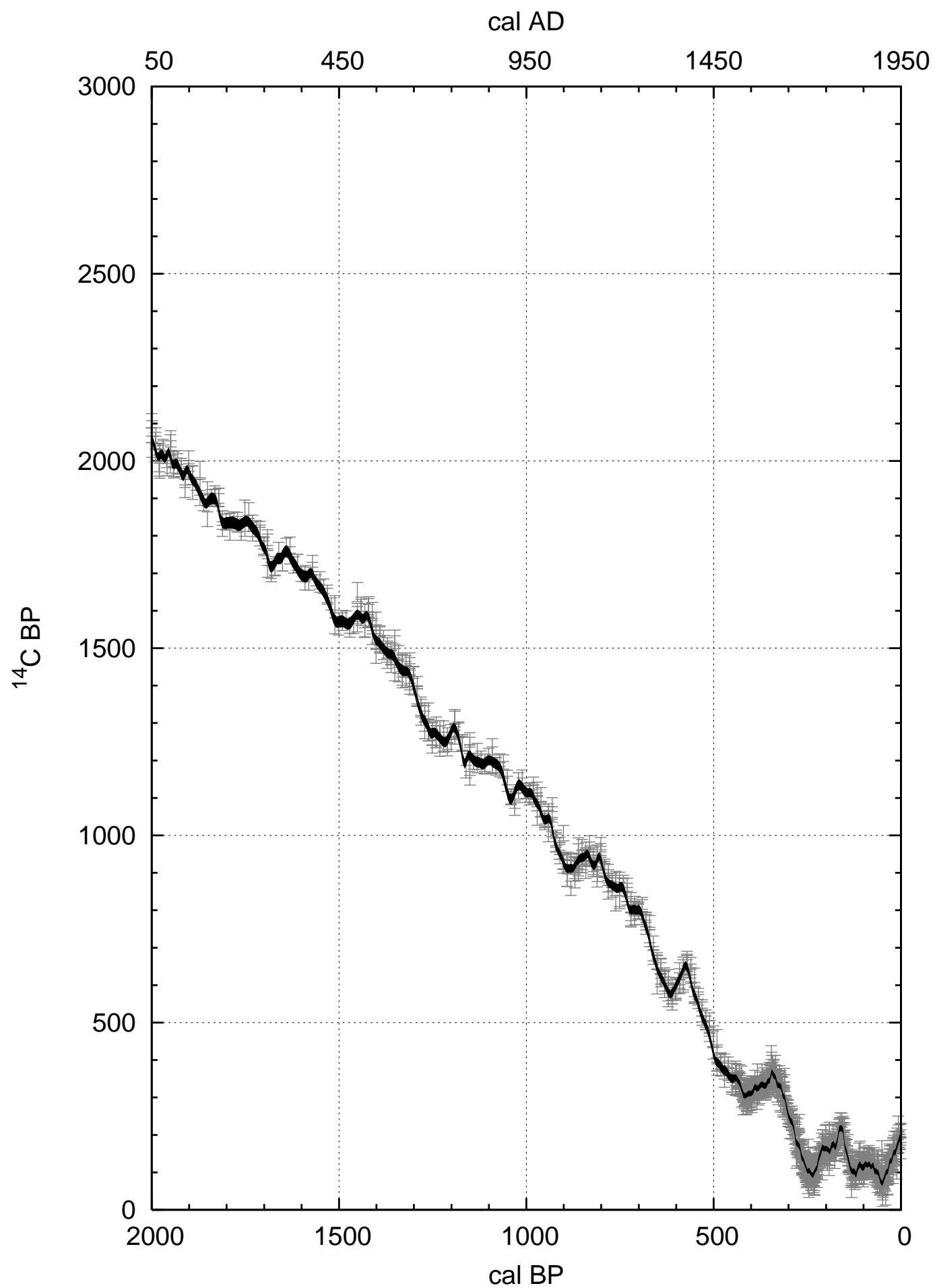

Figure A13 The IntCal04 terrestrial calibration curve (1-standard deviation envelope) and data with 1-standard deviation error bars in ${ }^{14} \mathrm{C}$ increased by the laboratory error multipliers described in the text. The uncertainty in the calendar ages is not shown, but is taken into account in the random walk model. 